\title{
Can Abies alba Needles Be Used as Bio-passive Samplers to Assess Air Quality?
}

Aerosol and Air Quality Research

\section{OPEN ACCESS}

Received: April 22, 2021

Revised: August 5, 2021

Accepted: September 7, 2021

${ }^{*}$ Corresponding Authors:

Agnieszka Stojanowska agnieszka.stojanowska@pwr.edu.pl Anita Urszula Lewandowska anita.lewandowska@ug.edu.pl

\section{Publisher:}

Taiwan Association for Aerosol Research

ISSN: $1680-8584$ print ISSN: 2071-1409 online

Copyright: The Author(s). This is an open access article distributed under the terms of the Creative Commons Attribution License (CC BY 4.0), which permits unrestricted use, distribution, and reproduction in any medium, provided the original author and source are cited.

\author{
Agnieszka Stojanowska ${ }^{1 *}$, Maciej Górka², Anita Urszula Lewandowska ${ }^{3 *}$, \\ Kinga Wiśniewska ${ }^{3}$, Magdalena Modelska², David Widory ${ }^{4}$ \\ ${ }^{1}$ Department of Environmental Protection, Wroclaw University of Science and Technology, 50- \\ 370 Wroclaw, Poland \\ ${ }^{2}$ Institute of Geological Sciences, University of Wroclaw, 50-205 Wroclaw, Poland \\ ${ }^{3}$ Institute of Oceanography, University of Gdansk, Division of Marine Chemistry and \\ Environmental Protection, 81-378 Gdynia, Poland \\ ${ }^{4}$ GEOTOP/Université du Québec à Montréal (UQAM), Montréal, Canada
}

\section{ABSTRACT}

Bio-passive samplers have proved to be good alternate to assess air quality in regions where the use of active samplers is not technically feasible. Here, we tested the potential for Abies alba (silver fir) needles to be used as reliable bio-passive samplers. As these evergreen coniferous trees do not lose their needles in winter these are representative of a full year period. Needle samples were collected in 2013 from 20 different locations within the Holy Cross National Park (Świetokrzyski Park Narodowy, Holy Cross Voivodship, Poland). Both needles and the aerosols deposited on their surfaces were analyzed for their $\delta^{13} C$. Additionally, total carbon (TC), elemental carbon (EC) and organic carbon (OC) were determined only in surface-impacted aerosols using thermo-optical method. The overall objective of our study was to evaluate the possibility to distinguish bio-organic aerosols (crushed needles) from anthropogenically derived aerosols. The highest aerosol mass concentration $\left(4.6 \pm 2.4 \mathrm{mg} \mathrm{g}^{-1}\right)$ was observed in samples with the longest exposure time, while the shortest exposure times yielded the lowest ones $\left(1.7 \pm 0.7 \mathrm{mg} \mathrm{g}^{-1}\right)$. Aerosols that were enriched in ${ }^{13} \mathrm{C}$, indicating the impact of human activities, were located close to inhabited areas, at highly elevated points and in places situated outside the park. Our results also prove that one-year-old needles are the most reliable isotope bioindicators. We ultimately recommend that Abies alba needles can be used in future air quality monitoring programs, especially since this method is low cost and easy to implement.

Keywords: Bioindicators, Abies alba needles, $\delta^{13} \mathrm{C}$, Aerosols

\section{INTRODUCTION}

Atmospheric particulate matter (PM) is one of the major air pollutants in Europe (EEA, 2019) and carbonaceous aerosols represent one of the major PM components. This carbonaceous fraction is usually subdivided into organic carbon (OC), the light-scattering fraction, and elemental carbon (EC), the light-absorbing fraction (Galindo et al., 2019; Xu et al., 2015). Carbonate carbon (CC) bond to carbonaceous particles is less frequent (Ozdemir et al., 2014). Organic carbon in atmospheric PM can originate from anthropogenic and natural sources and can be divided into two types: primary $\mathrm{OC}$, emitted directly into the air and secondary $\mathrm{OC}$, resulting from the secondary oxidation of VOCs by i.e., $\mathrm{O}_{3}, \mathrm{NO}_{2}, \mathrm{OH}$ (Murillo et al., 2013; Kucbel et al., 2016). Primary OC derives from natural biogenic sources (i.e., pollen, bacteria, viruses, several types of fungal spores, plants and fragments of insects) (Schwarz et al., 2008). Secondary extractable OC, which includes VOCs from natural sources and anthropogenic compounds, should also be mentioned (Schauer et al., 2007). Elemental carbon is a primary pollutant created directly from the incomplete combustion of fossil fuels or biomass (Galindo et al., 2019). EC is characterized by a porous structure 
(Murillo et al., 2013), which facilitates its adsorption of toxic compounds (Lucking et al., 2011; Mills et al., 2011). EC can be transported over thousands kilometers from its source, increasing its environmental impact (Husain et al., 2007). Considering that, carbonaceous aerosols are of much interest when studying air quality. Another issue is analysis of carbon isotopes which can contribute to discrimination of the different sources of aerosols and has now been widely documented (e.g., Aguilera and Whigham, 2018; Górka et al., 2012; Lim et al., 2020; MoreraGómez et al., 2018; Widory et al., 2004). These studies are based on the analysis of the different carbon isotope systematics: stable carbon isotopes ${ }^{12} \mathrm{C},{ }^{13} \mathrm{C}$ (e.g., Aguilera and Whigham, 2018; Morera-Gómez et al., 2020) and/or radiocarbon ${ }^{14} \mathrm{C}$ (Lim et al., 2020). Among the different sources, $\mathrm{C}_{3}$ plants (in which the first product of the $\mathrm{CO}_{2}$ assimilation during photosynthesis is a 3phosphoglycerate - compound) are characterized by $\delta^{13} \mathrm{C}$ from $-34 \%$ o to $-24 \%$ (with an average of $-27 \%$ o (e.g., Šturm et al., 2012; Zhang et al., 2019). The major anthropogenic emission sources generate particles with the following typical $\delta^{13} \mathrm{C}$ isotope compositions: (i) coal, between $-24.2 \%$ 。 (poor quality coal) and $-25.7 \%$ o (high quality coal), while the corresponding soot has a $\delta^{13} \mathrm{C}$ of $-24.5 \%$ o (Górka and Jędrysek, 2008); (ii) diesel particles, from -26.5\%o (Widory et al., 2004) to -28.3\%。 (Górka and Jędrysek 2008); (iii) unleaded fuel particles, from -24.2\%o (Widory et al., 2004) to -26.8\%o (Górka and Jędrysek, 2008).

It has now clearly been established that PM affects climate, the ecosystems and human health, especially in populated areas where it is present in significant concentrations (Atkinson et al., 2015). Usually, such areas are under continuous control of the influence of anthropogenic sources. However, the rural sites can be also under serious risk in terms of air pollution but, unlike urban or industrial areas, they are usually not monitored. European Union requires that its member countries monitor their $\mathrm{PM}_{10}$ and $\mathrm{PM}_{2.5}$ emissions as well as their ambient air concentrations (EEA et al., 2018). In order to reach these objectives, active methods, which are based on a dynamic sampling and that require the use of a pumping device by which air passes through either an air sample container or a filter, are generally recommended. These methods are relatively expensive and require specific instrumentation. Hence, in some regions (e.g., mountain or woody) the implementation of this active sampling is often impossible due to the lack of access to electricity, altitude or limited access. The difficulty can be alleviated by the use of living organisms or their products (bioindicators) that are present in the targeted study areas. The use of bioindicators to monitor/assess the quality of different environments offers other advantages such as the possibility of bio-concentrating both organic and inorganic contaminants and of accessing time-integrated information (Conti and Cecchetti, 2001). Similarly to aerosol samples, bioindicators will yield information about the origin of the atmospheric particulate matter, from which the corresponding anthropogenic impact can be evaluated for a given area and time period. Bioindicators have already been proven to be excellent environmental proxies, from which pertinent information can be obtained by studying their carbon isotope compositions (e.g., Brendel et al., 2003; Ciężka et al., 2016). There are many kinds of different bioindicators, for example: lichens (e.g., Kłos et al., 2007; Ciężka et al., 2018; Kłos et al., 2018), mosses (e.g., Kłos et al., 2018; Maxhuni et al., 2016; Shetekauri et al., 2018), spider webs (Bartz et al., 2021; Górka et al., 2018; Stojanowska et al., 2020; Stojanowska et al., 2021). Also tree leaves and needles are considered useful bioindicator (Górka et al., 2020; Lehndorff and Schwark, 2004; Wang et al., 2015; Wuytack et al., 2010) as they have the capacity to accumulate particulate matter on their surface, that is further trapped by being covered with epicuticular wax (Zeisler-Diehl et al., 2018). Tree needles are recording information about their surrounding air quality, such as potentially toxic elements or, indirectly, the carbon isotope compositions of depositing aerosols (e.g., Sensuła et al., 2018; Vladimirovna Afanasyeva and Ayushievna Ayushina, 2019). The fact that the vegetation is highly spatially and temporally distributed makes it easily accessible and inexpensive in biomonitoring approaches (Sawidis et al., 2011). Conifers are generally considered good bio-passive samplers as many of them are evergreen trees, i.e., they do not lose their needles in winter (Mauri et al., 2016). Consequently, monitoring air quality using their needles can be carried out on a full year scale. The needles' adsorption potential is enhanced by the morphology of the conifers canopies, as they are dense and fine-textured with a high leaf area index (Yang et al., 2015). To our knowledge, no study has ever been conducted on carbonaceous aerosols collected on needles, and in particular focusing on their carbon geochemistry and isotope compositions. With that in mind, our objective was to evaluate the possibility of using Abies alba needles as alternate 
bioindicators to study air quality, using an approach that coupled the $\delta^{13} \mathrm{C}$ from the needles and the aerosols adsorbed onto their surface with the total carbon (TC), elemental carbon (EC) and organic carbon $(\mathrm{OC})$ contents of the aerosols.

\section{MATERIALS AND METHODS}

\subsection{Study Area}

Samples were collected in the Holy Cross National Park, located in the Holy Cross Voivodship, central Poland (Fig. 1). Several major emission sources are located in the vicinity of the study area (Fig. 1): power stations in Kielce, Połaniec, Jaworzno and Bełchatów; a steel plant in Ostrowiec; sulphur chemical plants in Grzybów and Tarnobrzeg; and a zinc smelter in Miasteczko Śląskie. Road traffic is another major local source of aerosols with an average of 8,500 cars/day driving the national roads of the Holy Cross Voivodship (GDDKiA, 2015). Heating in the Voivodship's single and multi-family buildings is mostly based on the combustion of poor-quality coal. The air quality in this region is also influenced by transboundary pollutant transport, mostly from the Lesser Poland and Silesian Voivodships, with carbon monoxide, nitrogen oxides and non-methane volatile organic compounds (NMVOC) representing the main transported compounds (Environmental protection program for the Holy Cross Province. Available at: https://bip.sejmik.kielce.pl/142departament-rozwoju-obszarow-wiejskich-i-srodowiska/4769-program-ochrony-srodowiska-dlawojewodztwa-swietokrzyskiego-na-lata-2015-2020-z-uwzglednieniem-perspektywy-do-roku2025.html; accessed September 16, 2019).

\subsection{Materials}

Abies alba (silver fir) was selected as it represents the most abundant tree in the Holy Cross National Park and its needles are easily accessible. All needle samples were collected in summer 2013 at 20 different locations: 18 in the National Park and 2 in its close vicinity (Fig. 1). At each sampling location, branches from a few trees (typically 5) were collected at a height about 1.52 meters above the ground and pooled to both homogenize the needle samples and obtain a sufficient amount of material for the subsequent analysis (generally $15 \mathrm{~g}$ ). The needles were packed in clean paper bags for transport. To avoid any potential canopy effect between the sampled trees, they were chosen within similar populations. In the laboratory, needles were divided by age classes (6-months old, referred as 2013; 1-year-old, referred as 2012; and older than 1 year, referred as $<2012$ ), weighed and stored in paper bags: 3 samples were thus obtained for each sampling location, for a total of 60 samples. The age division was made taking into consideration the needle growth on branches and the noticeable separation of their individual annual increments. This also allowed to obtain samples with different aerosol collection times that later will permit testing the needle potential and efficiency for collecting aerosols. This protocol for separating needles was adapted from Brendel et al. (2003) and Muukkonen and Lehtonen (2004).

\subsection{Methods}

\subsubsection{Samples preparation}

Aerosols were washed out of the needles' surface using distilled water as previous studies demonstrated that this washing agent gives satisfying results (e.g., Al-Alawi and Mandiwana, 2007; Ataabadi et al., 2011; Leśniewicz and Zyrnicki, 2000). In brief, 15 g of needles were placed into a beaker. $300 \mathrm{~mL}$ of distilled water were added and the beaker was gently mixed with a glass rod for 5 minutes. This five-minute mixing was determined by trial and error: longer than 5' caused a large number of needles to crumble, while a shorter time resulted in a low aerosol yield. The solution was then filtered through a QM-A quartz fiber filter (diameter of $47 \mathrm{~mm}$, porosity $2.2 \mu \mathrm{m}$, Whatman) under vacuum. Quartz fiber filters were not baked before collection according to the fact that previous studies from our research group demonstrated that blank filters yielded carbon contents under the CM-CRDS detection limit. After filtration filters were dried in an oven at $45 \pm 2{ }^{\circ} \mathrm{C}$ and stored in a desiccator until further treatment and analysis. The filters were double weighed before and after the filtration using a Vibra HTR-220CE $\left( \pm 0.1 \mathrm{mg}\right.$, at $23 \pm 2^{\circ} \mathrm{C}$ and relative humidity of $40 \pm 5 \%$ ), yielding the mass of particulate matter adsorbed on the needles. The final PM quantity was expressed as milligrams of aerosols per gram of dry needles. 


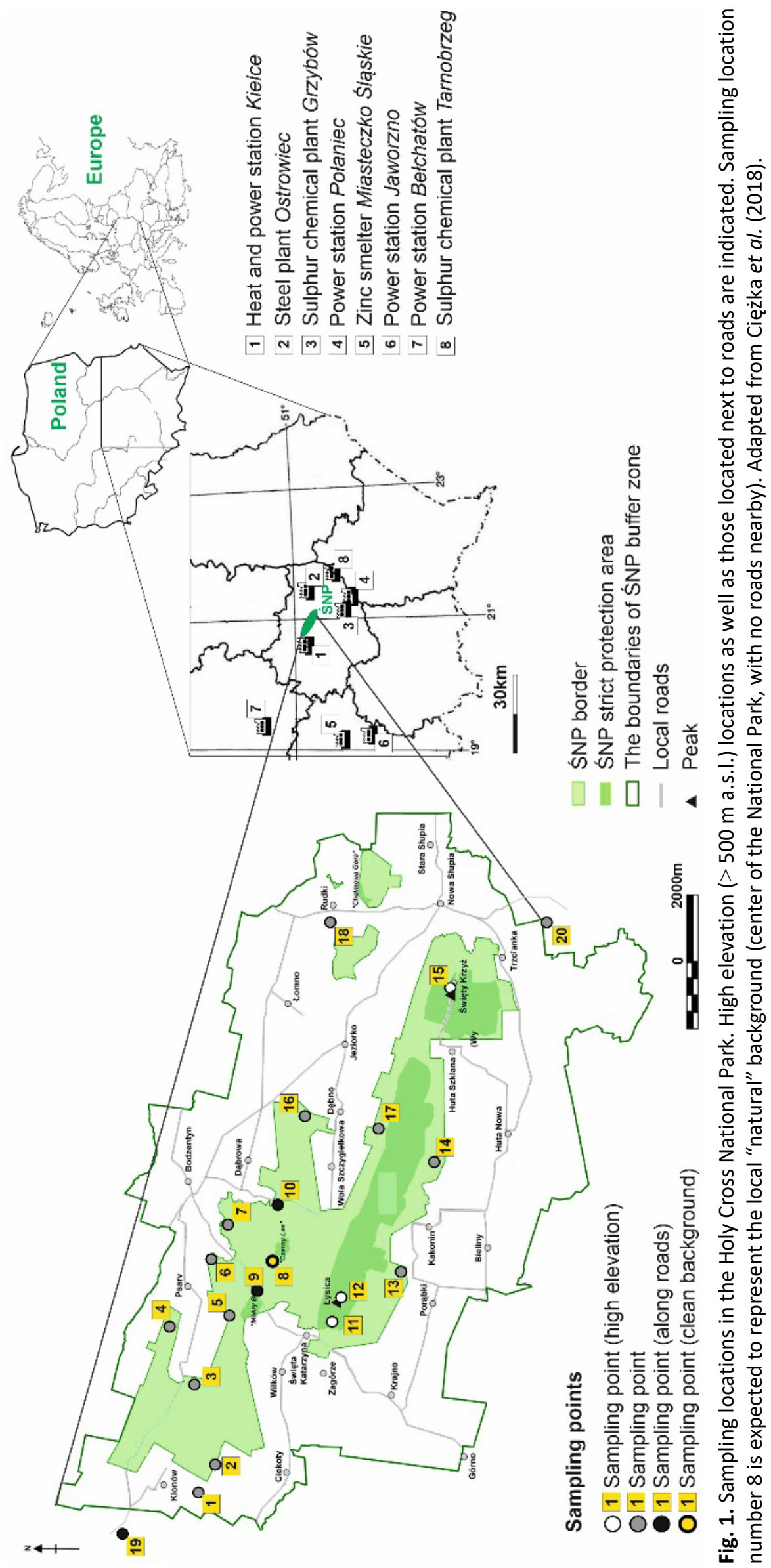




\subsubsection{Carbon stable isotope analysis $\left(\delta^{13} \mathrm{C}\right)$ of aerosol and needle samples}

$\delta^{13} \mathrm{C}$ isotope compositions were determined by Cavity Ring-Down Spectroscopy (CRDS) coupled to a combustion module. For filter samples, a punch was cut using an IVA Analysentechnic puncher. Needle samples were homogenized by grounding them in a clean fine grit mill. Both the size of the punch and the mass of grounded needles were adjusted during each run to ultimately obtain $\sim 2000-4000 \mathrm{ppm}$ of $\mathrm{CO}_{2}$ generated by the combustion process. For the carbon stable isotope analysis, the filter punch or the needle powder was placed into a tin capsule that was sealed and analyzed using a Picarro G2201-i CRDS analyzer coupled with a CM (combustion module). Carbon isotope compositions were expressed as $\delta^{13} \mathrm{C}$ values, which represent the relative difference expressed in per mil (\%) between the isotope ratio of the sample and that of the Pee Dee Belemnite (PDB) standard:

$\delta^{13} \mathrm{C}(\%$ ovs.PDB $)=R_{\text {sample }} / R_{P D B}-1 \times 1000$

$\delta^{13} \mathrm{C}$ values were calibrated using certified standards NBS-19 $\left(\delta^{13} \mathrm{C}=+1.95 \%\right)$, NBS-18 $\left(\delta^{13} \mathrm{C}\right.$ $=-5.014 \%)$, IAEA CO-8 $\left(\delta^{13} \mathrm{C}=-5.764 \%\right)$, USGS-24 $\left(\delta^{13} \mathrm{C}=-16.049 \%\right)$ and USGS-40 $\left(\delta^{13} \mathrm{C}=\right.$ $-26.389 \%$ ). Analyses were made on 2 to 4 replicates and the associated analytical error on the measured $\delta^{13} \mathrm{C}$ was $<0.2 \%$.

\subsubsection{Total carbon, organic carbon and elemental carbon quantification in aerosols}

Total carbon (TC), elemental carbon (EC) and organic carbon (OC) were determined using a Sunset Laboratory Dual-Optical Carbonaceous Analyzer at the University of Gdansk (Division of Marine Chemistry and Environmental Protection, Institute of Oceanography). We followed the EUSAAR2 protocol, owing to the optimal maximum temperature obtained at the end of the first stage, which corresponded to $650^{\circ} \mathrm{C}$, and ensured that only $2.5 \pm 2.4 \%$ of the elemental carbon was combusted during the first stage of analysis (Cavalli et al., 2010). A $1.5 \mathrm{~cm}^{2}$ rectangular piece of the quartz fiber filter was placed into a quartz oven, where it was analyzed for both OC and EC. The method's limit of detection (MLD) was $0.3 \mu \mathrm{g} \mathrm{cm}^{-2}(\mathrm{n}=72)$ for both OC and EC, while the analytical error was $<6 \%$ for EC and $<10 \%$ for OC (with a $99 \%$ confidence interval). All carbon results were corrected for blanks: $3.0 \mu \mathrm{g} \mathrm{cm}^{-2}$ for OC while no correction was necessary for EC as blanks were under the MLD. Apart from automatic calibration (internal standard: $5.0 \%$ methane in equilibrium with analytically pure $\mathrm{He}$ ), which takes place at the end of the second stage of the analysis, an external standard was analyzed (99\% analytically pure sugar solution) after every 1015 samples. The average analytical error of the external calibration was $4.5 \%$. Additionally, an inter-laboratory comparison using an Elemental Analyzer Instruments NC 2500 NC at the Université du Québec a Montréal (UQAM) was performed. The agreement between the two methods was confirmed by a high Pearson correlation coefficient value for total carbon ( $r>0.9)$. More details can be found in our previous publications (Lewandowska et al., 2018; Wiśniewska et al., 2019).

\subsubsection{Isotope mass balance calculation}

We performed an Isotope Mass Balance (IMB) to estimate the respective contributions of the following 2 endmembers on the final $\delta^{13} C_{\text {aerosols }}$ we measured: contamination (i.e., external) and biogenic (i.e., needle). Contributions were calculated using the following equation:

IMB $=\mathrm{a} \times \delta^{13} \mathrm{C}_{\text {source }}+\mathrm{b} \times \delta^{13} \mathrm{C}_{\text {needles }}=\delta^{13} \mathrm{C}_{\text {aerosols }}$

where $\delta^{13} C_{\text {aerosols, }} \delta^{13} C_{\text {needles }}$ and $\delta^{13} C_{\text {source }}$ are the $\delta^{13} \mathrm{C}$ of the aerosols, needles and of the corresponding aerosol emission source. "a" is the percentage contribution of the contaminant source and " $b$ " the one of particles resulting from the eventual inclusion of needle debris during the sample preparation, when needles are washed with distilled water.

\subsubsection{Statistical analysis}

We used the Kruskal-Wallis test to highlight differences between dust concentrations with respect to the different needle age classes. To discriminate groups, multiple pairwise-comparisons 
using the Dunn's test were applied. These median tests are the non-parametric equivalent of ANOVA and allow to evaluate differences between more than 2 variables. Test were performed on the 60 samples using the computing environment R ( $R$ Core Team, 2013; additional software packages tidyverse, ggpubr, rstatix and ggplot2 were used). Multivariate Principal Component Analysis (PCA) was performed on 5 standardized parameters measured in dust (for 2012 needles): dust concentration, TC, EC, OC and $\delta^{13} \mathrm{C}$. The objective of the PCA (Statistica 13 software) was to identify the interrelated factors characterizing the processes controlling the dust carbon chemical and isotope compositions. Transformation factor loads matrix (varimax rotation; Table 3) and factor scores values (Fig. 9) were calculated (Cattell, 1966; Drever, 1997; Johnson, 1978). As it was demonstrated by Manly (1998) PCA requires a limited number of useful variables and it helps to describe relations amongst them. The PCA results were considered reliable due to the high number of samples (58) analysed, the observed normal distribution (for $\delta^{13} \mathrm{C}$ ) or close to normal or lognormal for the other data, and the correct conditioning of the matrix as well as eigenvalues close to 1 for the parameters. The Surfer 10.0 software was used to create the isoline maps (Figs. 3, 5, and 7), applying an ordinary kriging method.

\subsubsection{Scanning electron microscope (SEM) analysis}

SEM analysis, on a randomly-selected subset of samples, was conducted in order to investigate i) if the our protocol (i.e., rinsing with distilled water) was efficient at washing out the aerosols deposited at the surface of the needle samples and ii) to verify that the surface of the needles had not been damaged by the subsequent stirring, which may have impacted the $\delta^{13} \mathrm{C}$ analysis. Fig. 2 reports the SEM images of the adaxial surface of the several-years-old samples $(<2012)$,

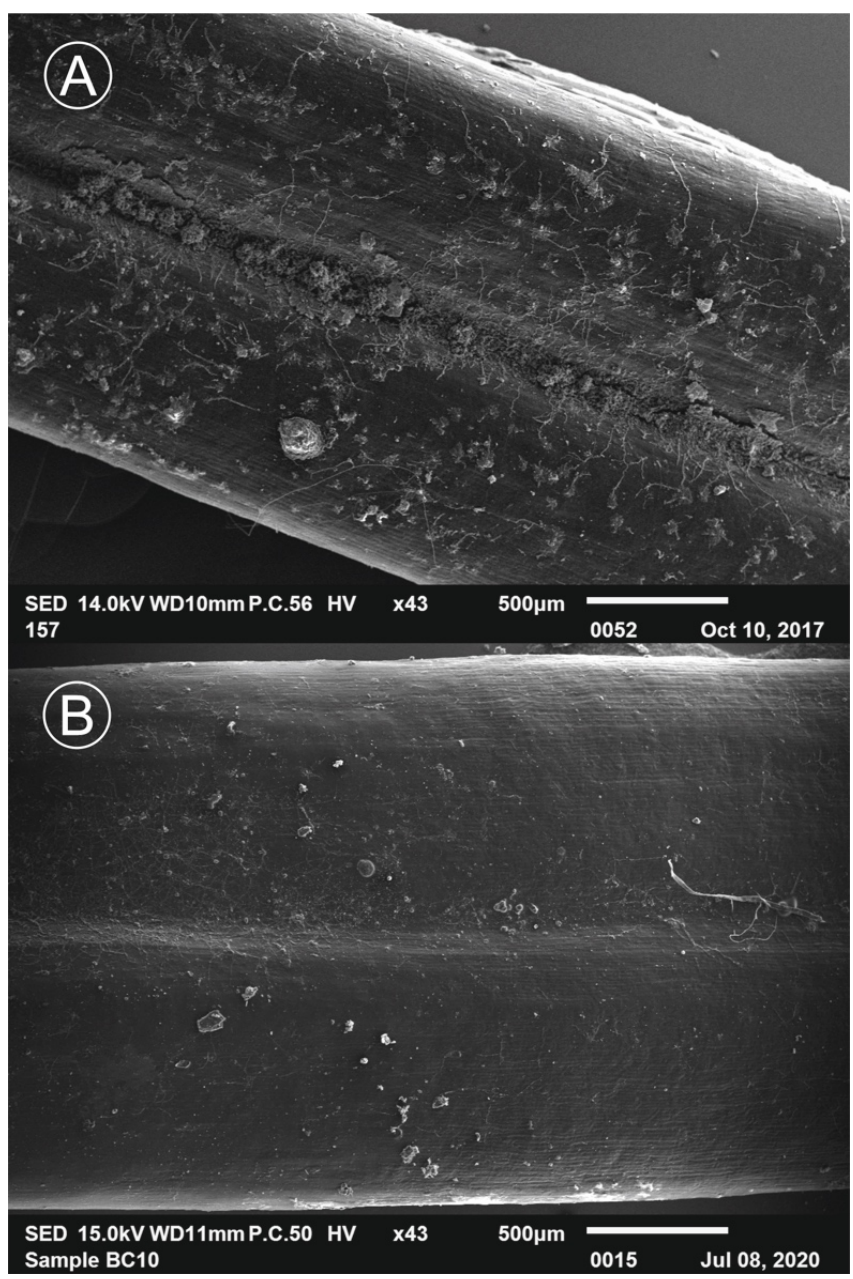

Fig. 2. SEM images (A) before and (B) after washing out with distilled water. The needle sample shown here corresponds to the age class $<2012$. 


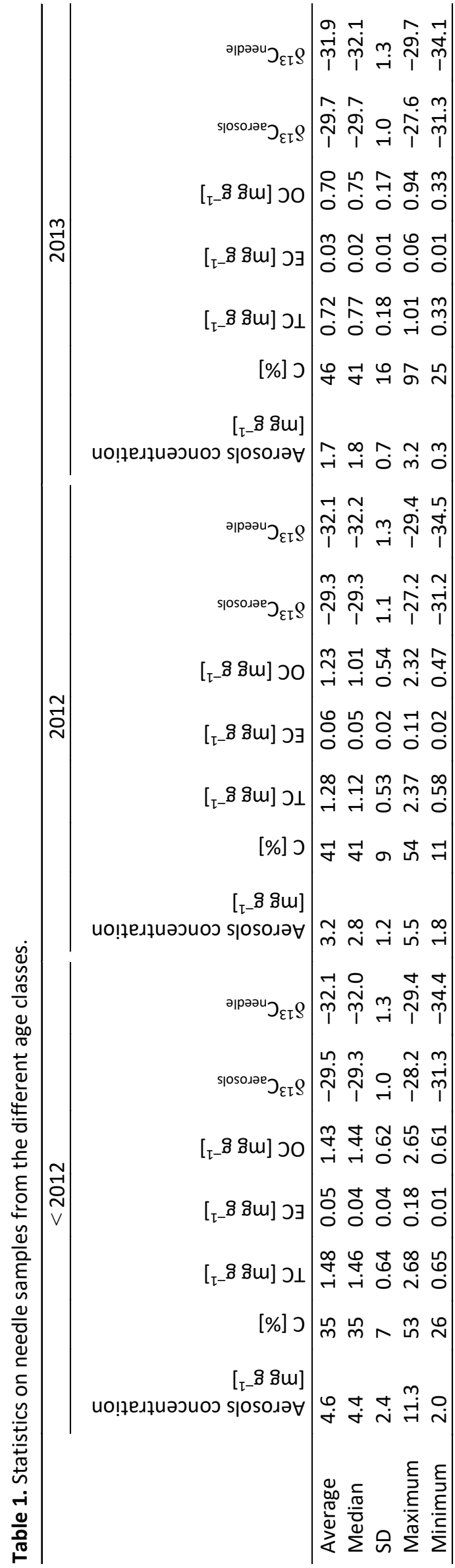

before (Fig. 2(A)) and after washing (Fig. 2(B)). The comparison between the two images confirms that aerosols were successfully washed out without damaging the surface of the needles although we acknowledge that some small quantities of needle fragments may still have been collected concomitantly with the aerosols.

\section{RESULTS}

\subsection{Aerosol Concentrations and TC, OC and EC Values}

Concentrations of aerosols adsorbed on the needle samples are reported in Table 1. The highest concentrations were on average $4.6 \pm 2.4 \mathrm{mg} \mathrm{g}^{-1}$ and corresponded to the oldest samples ( $<2012 ;>1$ year). In contrast, the lowest concentrations (average of $1.7 \pm 0.7 \mathrm{mg} \mathrm{g}^{-1}$ ) corresponded to samples collected in 2013, the shortest exposure time of our study ( $<1$ year). The aerosol concentrations measured for the year 2012 ranged from 1.8 to $5.5 \mathrm{mg} \mathrm{g}^{-1}$, with an intermediate average value of 3.2 $\pm 1.2 \mathrm{mg} \mathrm{g}^{-1}$.

In the case of TC, EC, and OC the results also varied depending on the age of the samples. The average TC results were as follows: $1.48 \pm 0.64 \mathrm{mg} \mathrm{g}^{-1}, 1.28 \pm 0.53$ $\mathrm{mg} \mathrm{g}^{-1}, 0.72 \pm 0.18 \mathrm{mg} \mathrm{g}^{-1}$ for $<2012,2012$, and 2013 respectively. The respective OC averages of $1.43 \pm 0.62 \mathrm{mg} \mathrm{g}^{-1}$ for samples older than 2012, $1.23 \pm 0.54 \mathrm{mg} \mathrm{g}^{-1}$ for 2012 and $0.70 \pm 0.17 \mathrm{mg} \mathrm{g}^{-1}$ for 2013 were noted (Table 1). The concentrations of EC were very low, revealing $0.05 \pm 0.04,0.06$ \pm 0.02 and $0.03 \pm 0.01 \mathrm{mg} \mathrm{g}^{-1}$ for $<2012$, 2012, and 2013 respectively.

\subsection{Aerosol and Needle Carbon Isotope Compositions}

The samples marked as older than 2012 were characterized by $\delta^{13} C_{\text {aerosols }}$ equal to $-29.5 \pm 1 \%$ and $\delta^{13} C_{\text {needle equal to }}-32.1 \pm$ $1.3 \%$. On the other hand, one-year old samples (2012) revealed averages of $\delta^{13} C_{\text {aerosols }}$ and $\delta^{13} C_{\text {needle }}$ equal to $-29.3 \pm$ $1.1 \%$ and $-32.1 \pm 1.3 \%$, respectively. The samples with the shortest exposure time yielded $\delta^{13} C_{\text {aerosols }}$ equal to $-29.7 \pm 1 \%$ and $\delta^{13} C_{\text {needle }}$ equal to $-31.9 \pm 1.3 \%$ (Table 1). 


\subsection{Concentrations of Adsorbed Aerosols}

It seems that results of concentrations of adsorbed aerosols are correlated to their age, i.e., exposure time to ambient air, with the shorter exposure times yielding lower PM concentrations (Table 1). The increasing trend observed for the aerosol concentrations on the surface of the needles confirm that they can be used as passive samplers for characterizing air quality. Previous studies have shown that plants in general play a significant role in removing atmospheric particulate matter (e.g., Nowak et al., 2013) due to their capacity to accumulate PM, which depends on the properties of the leaf surfaces (Wang et al., 2015). Leaf and needle surfaces consist of cuticles and an epicuticular wax, the outer surface of the cuticle (Buschhaus and Jetter, 2011; Zeisler-Diehl et al., 2018) that protect plants from water loss, UV light and abiotic stress factors (Zeisler-Diehl et al., 2018). The structure of the needle surface facilitates the adsorption of aerosols and once deposited they are not easily removed by wind or rainfall. Moreover, aerosols, deposited on the needle surface can block the suprastomatal chambers (Teper, 2009). This may lead to i) a decrease in the photosynthesis rate by reducing sunlight availability, ii) an increase in the leaf temperature triggered by changes in the surface optical properties, and iii) a modification of gas diffusion into and out of the leaves (Prajapati and Tripathi, 2008; Squires, 2016).

As a result, the basic functions of the plant are disrupted and the damaged fragments become susceptible to fungal infections (Teper, 2009). If needle samples are covered by fungi this may ultimately limit their potential to adsorb aerosols.

Additionally, the concentrations of adsorbed aerosols in our study area varied greatly, seemingly depending on the proximity to anthropogenic sources (Fig. 3). Ciężka et al. (2018) previously studied air quality in the Holy Cross National Park using passive samplers ( $\mathrm{NO}_{2}$ and $\mathrm{SO}_{2}$ concentrations) and bioindicators (heavy metals in Hypogymnia physodes). The authors concluded that air quality in our study area is impacted by emissions from local and regional anthropogenic sources (fossil fuel combustion; Ciężka et al., 2018): i) the impact of gaseous pollutants increased during heating season; ii) higher $\mathrm{NO}_{2}$ concentrations were observed along roads; iii) higher $\mathrm{SO}_{2}$ concentrations were observed at higher elevations; and iv) the highest $\mathrm{Zn}, \mathrm{Pb}$ and $\mathrm{Cu}$ concentrations in bioindicators were recorded at high altitude and were linked to long-range transport. Our results are showing similar trends, independently of the age of the needles (Fig. 3). Still, Fig. 3 shows that aerosol concentrations were higher in the older needle samples and seem positively related to their age (i.e., exposure time).

The lowest aerosol concentrations were observed in 6-months old samples (2013; Fig. 3(A)). The samples were collected during the summer 2013, implying that in these 6-months old samples the corresponding adsorbed aerosols were mainly emitted by natural sources or/and resulted of long-range transport, but were not linked to emissions from home-heating. The one-year-old samples (2012) revealed the highest aerosol concentrations at sampling locations 4, 12 and 13 (Fig. 3(B)). These same sampling locations were also characterized by the highest aerosol concentrations for samples with the longest exposure time (Fig. 3(C)). This may result from transboundary transport: sampling location 12 is the highest elevation while sampling location 4 is located in the close vicinity of an inhabited area. Pairwise comparisons using the Dunn's test showed that among the needle groups, the $<2012$ and 2013 group and the 2012 and 2013 groups were significantly different (Fig. 4).

\subsection{Aerosol and Needle Carbon Isotope Compositions}

Our results show that aerosols adsorbed on the needles were enriched in ${ }^{13} \mathrm{C}$ (i.e., higher $\delta^{13} \mathrm{C}$ ), especially for samples collected close to inhabited areas $(3,4,6)$, at the station located outside the park (20) as well as at the high-elevation ones (11, 12 and 15) (Fig. 5). For this latest group of samples, the increase in the $\delta^{13} \mathrm{C}$ may be associated to transboundary contamination. Southwestern winds dominate in the study area (Olszewski et al., 2000) and bring air pollutants from other Voivodships (especially from the Lesser Poland and the Silesian ones). This hypothesis is comforted by the fact that the highest $\delta^{13} \mathrm{C}$ we measured corresponded to locations in the southern part of the park (around sampling location 15 and further south; Fig. 5).

Variations of the $\delta^{13} C_{\text {needle }}$ were as follows: i) for the oldest samples $(<2012)$ carbon isotope 


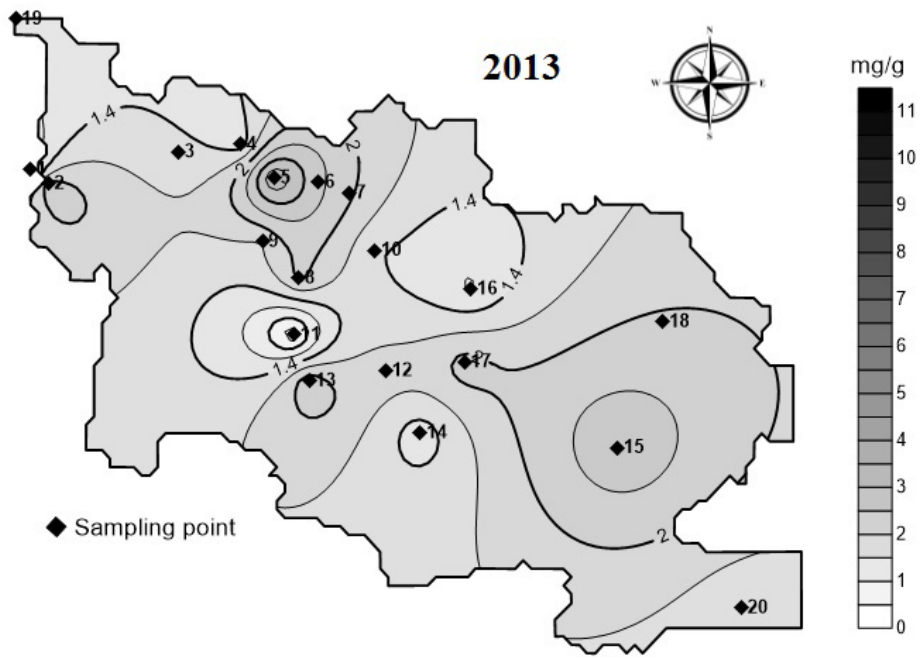

A

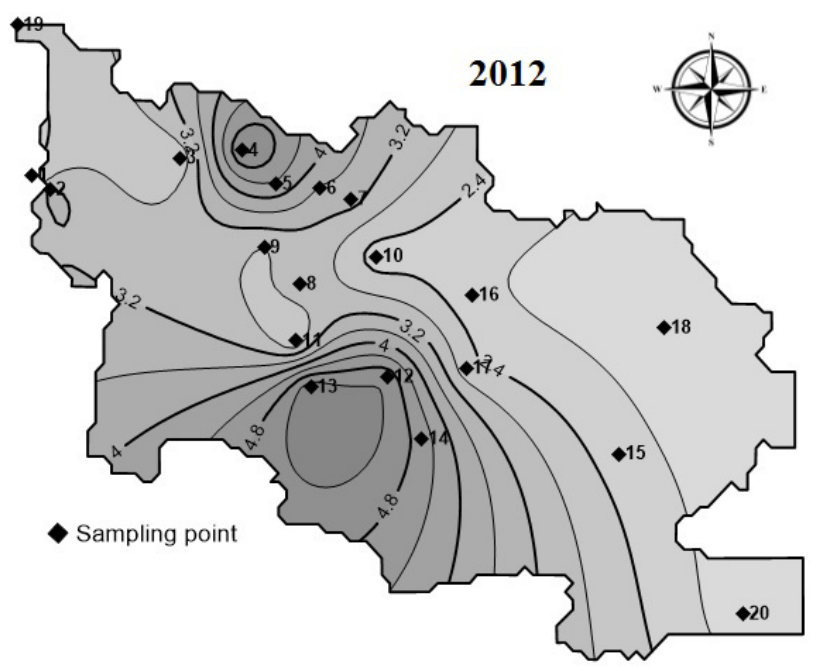

B

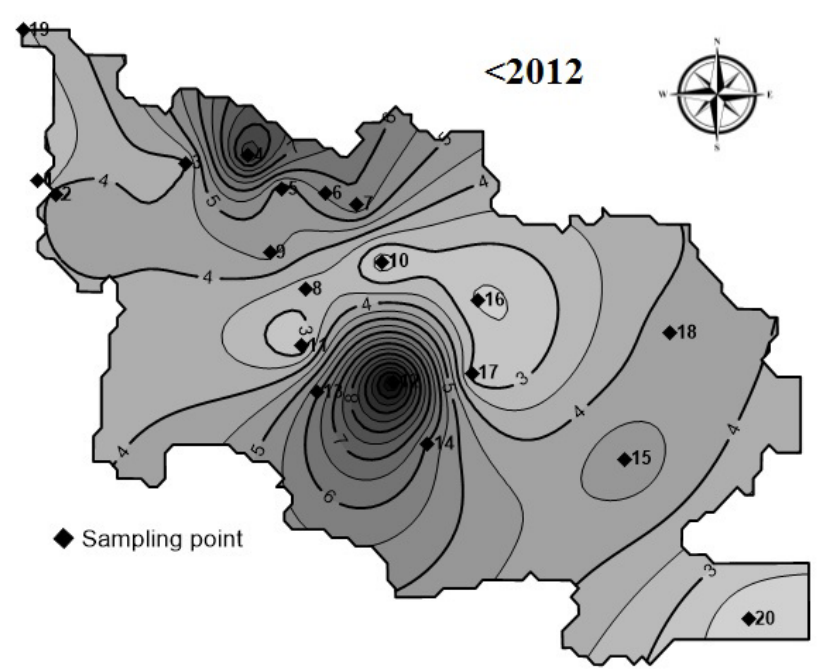

(C)

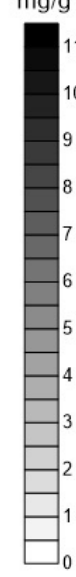

Fig. 3. Concentrations of aerosols deposited on needle samples. (A) 2013 samples, (B) 2012 samples, (C) $<2012$ samples.

compositions varied between -34.4 and $-29.4 \%$, ii) 2012 samples varied between -34.5 and $-29.4 \%$ and $\mathrm{iii)}$ those of 2013 between -34.1 and $-29.7 \%$. However, while we observed small variations in the average $\delta^{13} C_{\text {needle }}$ values (around $\pm 0.2 \%$, i.e., similar to the analytical error), 


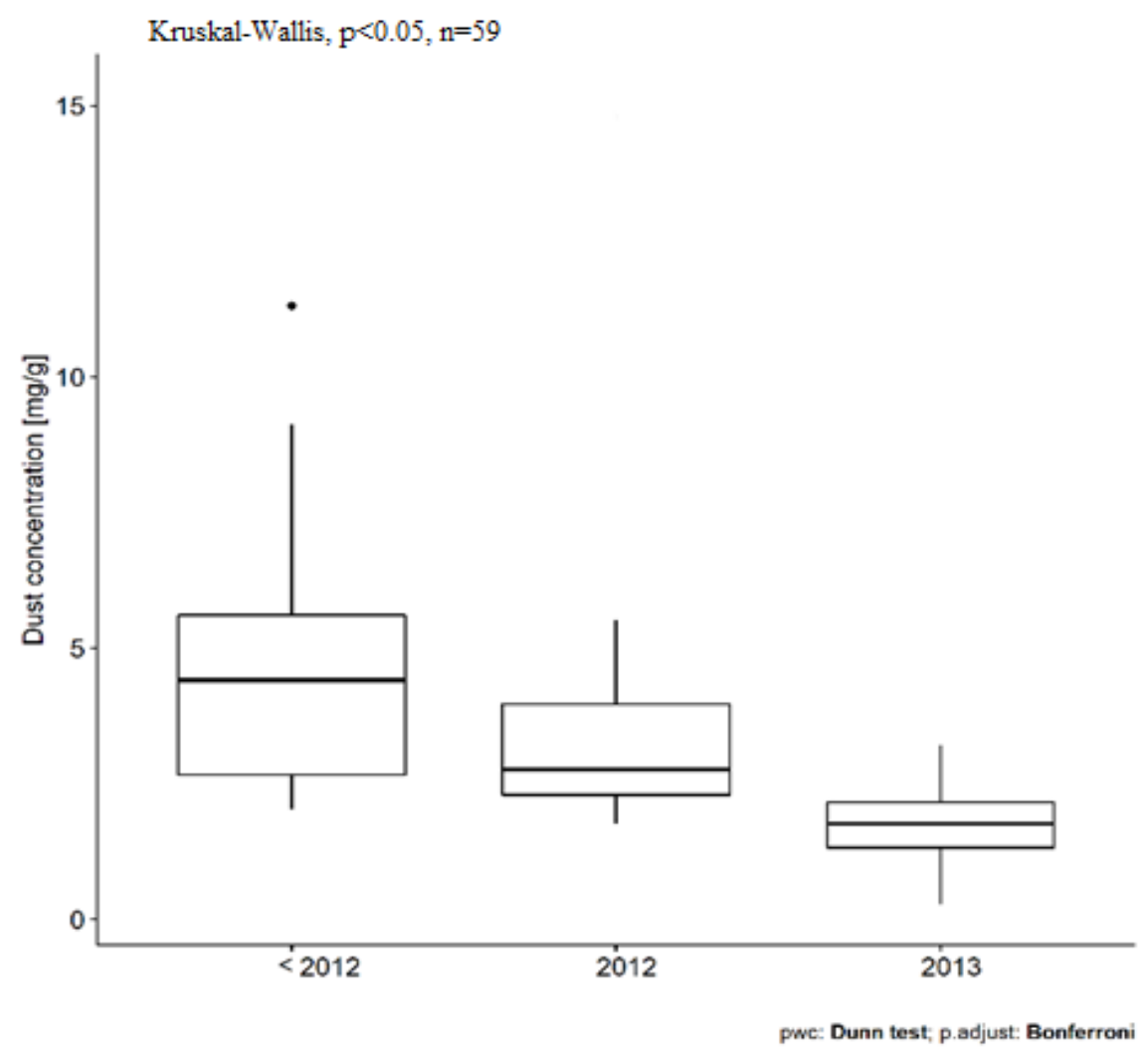

Fig. 4. Distribution of the aerosol concentrations as a function of the needle age.

differencing the different sampling years was not possible. In fact, the $\delta^{13} C_{\text {needle }}$ variations seemed more correlated to the sampling location than to exposition duration. Isotope variations generally result from numerous factors. One of them could be the Suess effect, which corresponds to a change in both the ${ }^{13} \mathrm{C}$ and ${ }^{14} \mathrm{C}$ ratios following the emissions of large amounts of fossil-fuel derived $\mathrm{CO}_{2}$, although its influence is not fully understood (Sensuła et al., 2018). The $\delta^{13} \mathrm{C}$ difference between needles of different ages from the same sampling locations did not exceed 1\%。 (SM Table 1). This may be explained by the fact that even if the time of sampling was the same (summer 2013) for all needle samples, the duration of their exposure to air pollution was different. Consequently, it was difficult to compare our results with previous similar studies, especially with that of Sensuła et al. (2018) who studied yearly collected needles (i.e., no variation in the duration of exposure to air pollution). Precipitations and humidity are two other important factors that control the $\delta^{13} \mathrm{C}$ of plants. Cuna et al. (2007) suggested that a higher amount of precipitations leads to a ${ }^{13} \mathrm{C}$-depletion (i.e., lower $\delta^{13} \mathrm{C}$ ) of the plant $\delta^{13} \mathrm{Corg}$. This comes from the fact that under humid conditions ${ }^{12} \mathrm{C}$-enriched components are preferably accumulated, inducing a negative correlation between the $\delta^{13} \mathrm{C}$ of the plant and the prevailing relative humidity (Cuna et al., 2007). Air humidity and soil moisture also control the $\delta^{13} \mathrm{C}$ values of tree rings (e.g., Gagen et al., 2007; McCarroll and Pawellek, 2001; Pazdur et al., 2013). Cuna et al. (2007) showed that elevation also impact carbon isotope compositions, showing that lichens collected at high elevations were enriched in ${ }^{13} \mathrm{C}$, and linked it to the increase in the atmospheric ozone concentrations with altitude: the excess of ozone induces a decrease in photosynthesis, leading to a ${ }^{13} \mathrm{C}$-enrichment. Ozone levels in Poland may vary depending on the time of year (GIOŚ, 2019). Finally, the canopy effect can also impact the $\delta^{13} C_{\text {needle, }}$ with the most negative values supposed to be measured close to the ground surface (Merwe and Medina, 1991). However, here, in order to cancel the canopy effect within each sampling location, we selected and sampled trees growing in groups within a similar population. To summarize, many distinct factors can influence the carbon isotope compositions of needles, making the interpretation of the $\delta^{13} C_{\text {needle }}$ values difficult. Here, while we did not observe a significant time-related isotope discrimination, the location of collection seems nevertheless to influence the measured $\delta^{13} C_{\text {needle. }}$. 

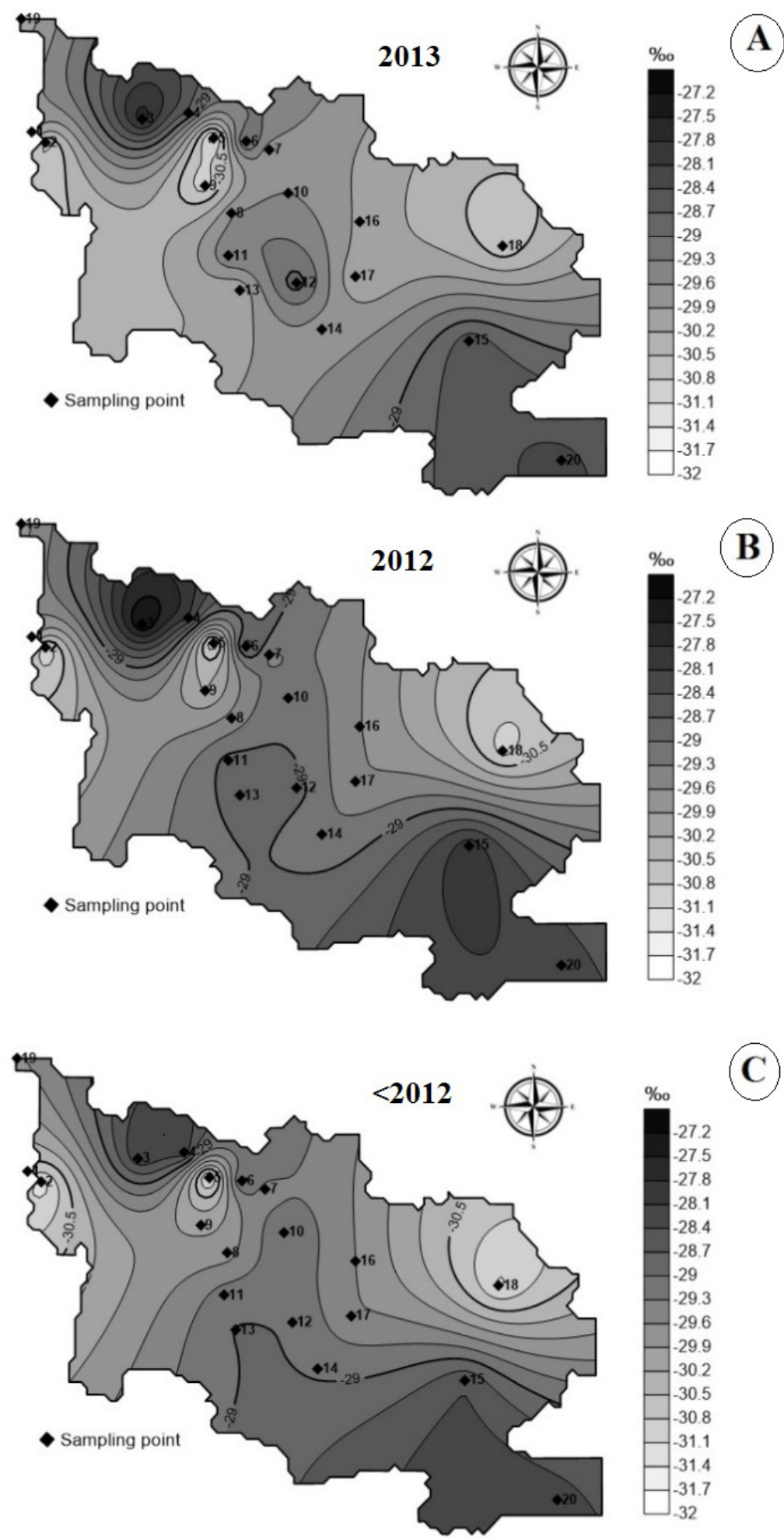

(C)

Fig. 5. Carbon isotope compositions $\left(\delta^{13} \mathrm{C}\right)$ of the deposited aerosols. (A) 2013 samples, (B) 2012 samples, (C) $<2012$ samples.

As discussed, the analysis of the $\delta^{13} \mathrm{C}$ of needles and aerosols may bring critical information about the corresponding contamination sources. But we first had to assure that the collected aerosol samples were not largely contaminated by crushed needles during the preparation protocol, which would artificially shift the $\delta^{13} \mathrm{C}$ value we are attributing to the aerosols. We hypothesized that $\delta^{13} \mathrm{C}$ of the deposited aerosols is different from that of needles. Additionally, we postulated that 
higher differences between $\delta^{13} C_{\text {aerosols }}$ and $\delta^{13} C_{\text {needle }}$ indicate a higher contribution of anthropogenic aerosols. Finally, we used a Isotope Mass Balance to estimate the respective contributions of the different contributing emission sources (Table 2 ).

As our old samples $(<2012)$ were covered by high amount of organic particles and those of 2013 represented only the vegetative season, the IMB was only run for the 2012 needles and their aerosols, as they were exposed to air contamination during both vegetative and heating season. We also ran the IMB considering two distinct scenarios for the source of air contamination: i) the emission source is local and mostly correspond to road traffic in the park. Its carbon isotope composition was calculated considering the respective particle contributions of typical Wroclaw road traffic (Central Statistical Office, 2013) and $\delta^{13} \mathrm{C}(-28.3 \%$ o for diesel and $-26.8 \%$ o for unleaded; Górka and Jędrysek 2008: $\delta^{13} C_{\text {source }}=2 / 3 \delta^{13} C_{\text {diesel }}+1 / 3 \delta^{13} C_{\text {unleaded }}=-27.8 \%$ o), ii) the emission source corresponds to home heating with a $\delta^{13} \mathrm{C}$ of $-24.5 \%$ (Górka and Jędrysek, 2008).

Previous studies have shown that using bioindicators in environmental monitoring impacts the size of the aerosols collected. Teper (2009) demonstrated that for pine needles most of the particles collected are $<10 \mu \mathrm{m}$ as larger ones are possibly washed out by rain. On the other hand, Freyer (1978) showed that, as deposition velocity is higher for fine or ultra-fine particles, conifers preferentially collect the coarse fraction. Moreover, Bartz et al. (2021) concluded that the fine fraction presents higher physical and chemical heterogeneities as it is generally connected to anthropogenic emissions. Ultimately, we can hypothesize that the fraction of fine aerosols collected on our pine needles was less abundant, rendering the identification of their emission sources difficult.

Results (Table 2) indicated that if we consider that calculated contributions $>70 \%$ are significant, road traffic (referred as the a1 value) had the strongest influence on sampling points located close to inhabited areas (3, 4, 6; Fig. 1), elevated areas $(11,15)$, at the sampling location outside the National Park (20) and at location 13. Also, for all samples the contribution of road traffic was dominant, the contribution of home heating being always secondary. Moreover, in scenario 2 the calculated $a_{2}$ values were almost always lower than the $b_{2}$ ones, which indicated a higher influence of particles from crushed needles. Sample 13, located in a residential area and very close to a busy road, identified significant contributions from both road traffic and home

Table 2. Isotope Mass Balance calculations, showing the respective contributions of the contaminant source and crushed needles in aerosol samples (i.e., one-year old samples (2012)).

\begin{tabular}{|c|c|c|c|c|c|c|c|}
\hline \multirow{2}{*}{ Sampling point } & \multirow{2}{*}{$\delta^{13} C_{\text {aerosols }}$} & \multirow{2}{*}{$\delta^{13} C_{\text {needle }}$} & \multirow{2}{*}{$\Delta_{\delta 13 \text { Caerosols }-\delta 13 \text { Cneedle }}$} & \multicolumn{2}{|c|}{ Road traffic } & \multicolumn{2}{|c|}{ Home heating } \\
\hline & & & & $a_{1}$ & $b_{1}$ & $a_{2}$ & $b_{2}$ \\
\hline 1 & -29.7 & -31.6 & 1.9 & 0.50 & 0.50 & 0.27 & 0.73 \\
\hline 2 & -31.1 & -33.1 & 2.0 & 0.38 & 0.62 & 0.24 & 0.76 \\
\hline $3 *$ & -27.6 & -29.4 & 1.8 & 1.16 & -0.16 & 0.38 & 0.62 \\
\hline 4 & -28.1 & -30.9 & 2.8 & 0.90 & 0.10 & 0.44 & 0.56 \\
\hline 5 & -31.2 & -33.9 & 2.7 & 0.45 & 0.55 & 0.29 & 0.71 \\
\hline 6 & -28.5 & -32.2 & 3.7 & 0.84 & 0.16 & 0.48 & 0.52 \\
\hline 7 & -29.4 & -32.8 & 3.4 & 0.69 & 0.31 & 0.41 & 0.59 \\
\hline 8 & -29.5 & -32.1 & 2.6 & 0.61 & 0.39 & 0.34 & 0.66 \\
\hline 9 & -30.2 & -33.7 & 3.5 & 0.59 & 0.41 & 0.38 & 0.62 \\
\hline 10 & -29.0 & -31.8 & 2.8 & 0.70 & 0.30 & 0.38 & 0.62 \\
\hline 11 & -28.9 & -32.3 & 3.4 & 0.76 & 0.24 & 0.44 & 0.56 \\
\hline 12 & -28.9 & -30.9 & 2.0 & 0.66 & 0.34 & 0.32 & 0.68 \\
\hline 13 & -28.9 & -34.5 & 5.6 & 0.84 & 0.16 & 0.56 & 0.44 \\
\hline 14 & -29.3 & -32.4 & 3.1 & 0.68 & 0.32 & 0.39 & 0.61 \\
\hline 15 & -27.9 & -31.0 & 3.1 & 0.98 & 0.02 & 0.48 & 0.52 \\
\hline 16 & -29.6 & -33.4 & 3.8 & 0.68 & 0.32 & 0.43 & 0.57 \\
\hline 17 & -29.6 & -32.6 & 3.0 & 0.63 & 0.37 & 0.37 & 0.63 \\
\hline 18 & -30.9 & -31.6 & 0.7 & 0.18 & 0.82 & 0.10 & 0.90 \\
\hline 19 & -29.8 & -32.3 & 2.5 & 0.56 & 0.44 & 0.32 & 0.68 \\
\hline 20 & -28.3 & -30.2 & 1.9 & 0.81 & 0.19 & 0.34 & 0.66 \\
\hline
\end{tabular}

* In this sampling point the mixture of diesel and unleaded has different proportion than the one assumed by us. 
heating, and was the only sampling location where these contributions ( $a_{1}$ and $\left.a_{2}\right)$ were higher than those of crushed needles ( $b_{1}$ and $b_{2}$ ).

Results also confirmed our hypothesis that the isotope difference $(\Delta)$ between the two isotope compositions ( $\delta^{13} C_{\text {aerosol }}-\delta^{13} C_{\text {needle }}$ ) is a good proxy of the anthropogenic impact. In the Holy Cross National Park, the highest $\Delta$ values were observed at sampling locations 13, 16, 6 and 9 with carbon isotope fractionations of 5.6\%, 3.8\% $3.7 \%$ and $3.5 \%$, respectively. Location 9 is in the immediate vicinity of a busy road. For sampling locations 6, 13 and 16 local home heating and road traffic were the most probable sources of contamination. To a lesser extent, lower but still significant $\Delta$ values were also observed at highly elevated sampling locations, which may indicate that their $\delta^{13} \mathrm{C}$ was controlled by air masses transported from distant areas or higher ozone concentrations.

\subsection{Relationships between $\delta^{13} C_{\text {aerosols }}$ and $\delta^{13} C_{\text {needle }}$}

Fig. 6 reports the $\delta^{13} \mathrm{C}$ variations of the total carbon between the needles and the deposited aerosols. Results show that deposited aerosols samples were all enriched in ${ }^{13} \mathrm{C}$ compared to the needles they were deposited on, which indicates that the collected aerosol particles were not dominated by needle-derived fragments.

Needle samples with several years of exposition were expected to yield the lowest $\delta^{13} \mathrm{C}$ values as their longer exposure time and subsequent accumulation of aerosols are propitious to fungal growth, that will ultimately impact their carbon isotope compositions. Meanwhile, one-year-old needle samples (2012, i.e., that were exposed to air pollution during growing and heating

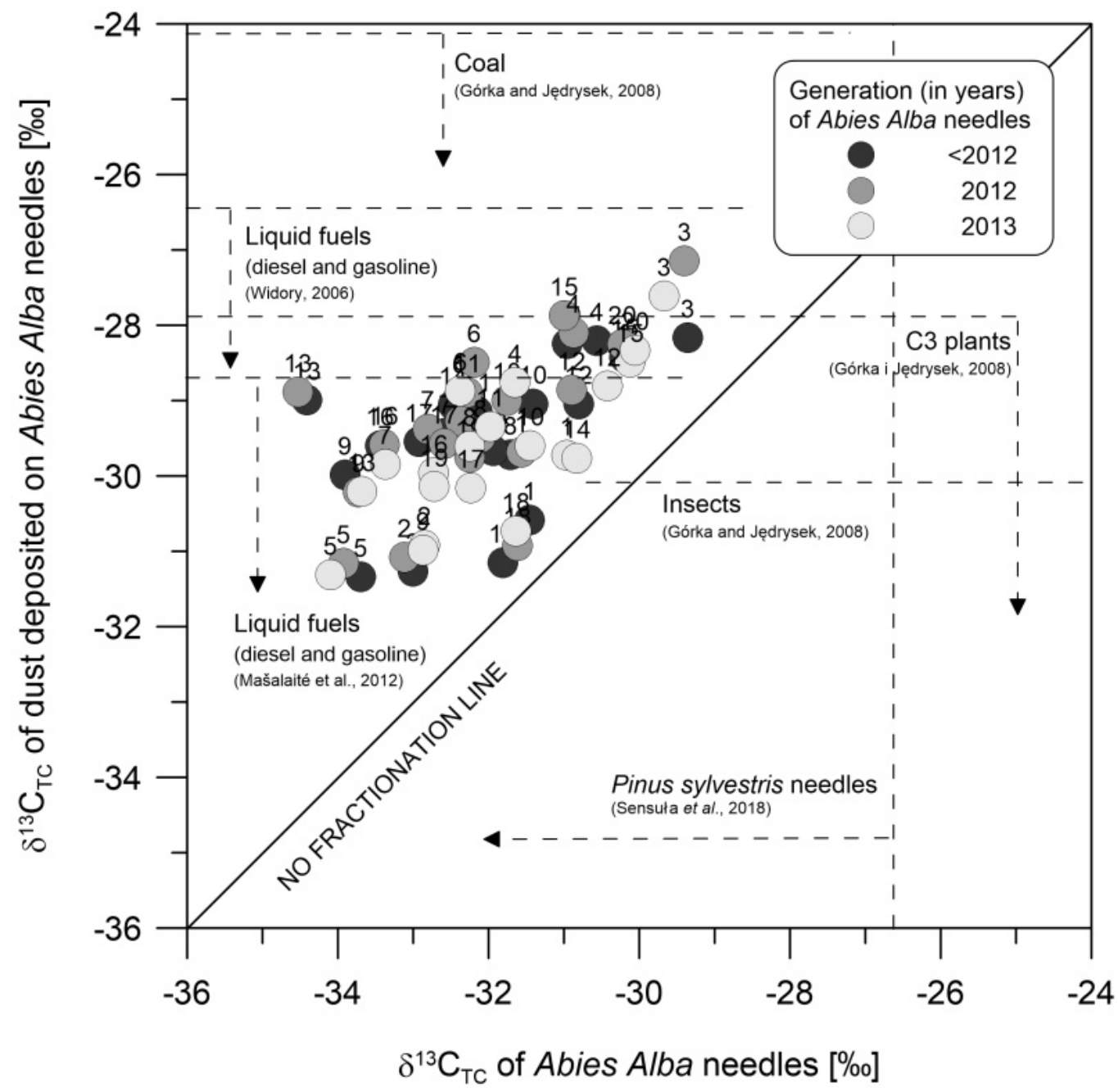

Fig. 6. Relationship existing between the $\delta^{13} \mathrm{C}$ of needles and that of deposited aerosols. 
seasons) were expected to record the highest $\delta^{13} \mathrm{C}$ values resulting from the incorporation of ${ }^{13} \mathrm{C}$ enriched aerosols from road traffic and home heating $\left(\delta^{13} \mathrm{C}>-24.5 \%\right)$. Finally, 6-months-old needle samples (2013; i.e., that were not exposed to emissions from heating sources) were expected to present $\delta^{13} \mathrm{C}$ values mostly corresponding to road traffic. Results from Fig. 6 show that only samples from location 3 follow this trend. Needle samples older than 2012 exhibited the greatest fungal growth, similar to the findings of Teper (2009), who suggested that this class of needles (i.e., older than one year) should not be used as isotope bioindicators due to their elevated amount of natural particles that ultimately modifies the final $\delta^{13} \mathrm{C}$.

\subsection{Total Carbon (TC), Organic Carbon (OC) and Elemental Carbon (EC) Concentrations}

The analysis of individual components in aerosols may bring more constrains on the respective sources of pollution involved within the study area. The average carbon content in our aerosol samples was $40.54 \pm 0.09 \%$, a relatively high value that may indicate that local air pollution results of coal combustion for heating purposes in the industry and communal sectors as well as of PM transport from surrounding areas. High inputs of carbon in PM has already been widely documented in Poland (e.g., Zimnoch et al., 2020; 31.3-67.5\% of TC in TSP) but also in Spain (e.g., Galindo et al., 2019; $26 \%$ of TC in $\mathrm{PM}_{10}$ and $48 \%$ of TC in $\mathrm{PM}_{1}$ ), Czech (Kucbel et al., 2016; 26-39\% of TC in $\mathrm{PM}_{10}$ ) and even in more remote areas such as China (e.g., Xu et al., 2015; 20\% of TC in PM 2.5 and 30\% of TC in PM0.25). While the highest TC concentrations (in SM Table S1) were observed in samples older than 2012 (from $0.65 \mathrm{mg} \mathrm{g}^{-1}$ (location 11) to $2.68 \mathrm{mg} \mathrm{g}^{-1}$ (location 14), average of $1.48 \pm$ $0.64 \mathrm{mg} \mathrm{g}^{-1}$ ), the lowest ones were measured in samples from 2013 (from $0.33 \mathrm{mg} \mathrm{g}^{-1}$ (location 11) to $1.01 \mathrm{mg} \mathrm{g}^{-1}$ (location 15), average of $0.72 \pm 0.18 \mathrm{mg} \mathrm{g}^{-1}$; Table 1). Samples from 2012 presented intermediate contents (from $0.58 \mathrm{mg} \mathrm{g}^{-1}$ (location 12) to $2.37 \mathrm{mg} \mathrm{g}^{-1}$ (location 13), average of 1.28 $\pm 0.53 \mathrm{mg} \mathrm{g}^{-1}$; Table 1). The fact that the highest TC concentrations were measured in the oldest samples probably results of a longer exposure time to aerosol deposition. On the opposite, the year 2013 when the lowest TC concentrations were obtained, lasted only the period of the vegetative season and thus was expectedly only impacted by emissions from road traffic. For the years encompassed by our needle samples the Regional Inspectorate for Environmental Protection (WIOŚ) reported negligible variations in the levels of atmospheric PM for the Holy Cross Voivodship area, with levels that did not exceed the EU guidelines (WIOŚ, 2012, 2013, 2014). Hence, we can conclude that aerosol accumulation on needles is linked to the duration of exposure rather than to any increase in the pollution level over the same period, in agreement with Teper (2009), who also showed that the mass of the particles deposited on needles increases with their age.

The presence of $O C$ in our samples could be associated with biogenic particles, volatile biogenic compounds from natural sources or with secondary processes taking place in the atmosphere (e.g., oxidation by $\mathrm{O}_{3}, \mathrm{OH}, \mathrm{NO}_{3}, \mathrm{NO}_{2}$; e.g., Kucbel et al., 2016). The highest $\mathrm{OC}$ concentrations were observed in samples older than 2012, were slightly lower in 2012 and the lowest ones in 2013 (Table 1). As dust particles damage the needle wax layer, they inherently block stomata that damages needles' conditions, and ultimately lead to the intensification of fungal growth on their surface (Bačić et al., 1999). The intensity of this fungi development is positively related to the needle exposure time to air pollutants (Teper, 2009). While we did not monitor the presence of fungi, Teper (2009) proved that a long exposure time can lead to the fast development of fungi and hence to an eventual increase in the $O C$ concentrations. The largest OC difference we observed between the oldest and the youngest samples however corresponds to an exposition time that was too short to allow for an abundant development of fungi. Hence, in the oldest samples high OC may be associated with a large amount of biogenic particles accumulated over time on the surface of the needles. For the oldest samples $(<2012)$ the OC concentrations varied between 0.61 (location 11) and $2.65 \mathrm{mg} \mathrm{g}^{-1}$ (location 14), average of $1.48 \pm 0.64 \mathrm{mg} \mathrm{g}^{-1}$; in 2012, from 0.47 (location 12) to $2.32 \mathrm{mg} \mathrm{g}^{-1}$ (location 13), average of $1.23 \pm 0.54 \mathrm{mg} \mathrm{g}^{-1}$; and in 2013 from 0.33 (location 11) to $0.94 \mathrm{mg} \mathrm{g}^{-1}$ (location 15), average of $0.70 \pm 0.17 \mathrm{mg} \mathrm{g}^{-1}$. Similarly to what we observed for the TC concentrations, the maximum OC values, for the three different periods, were measured for the exact same samples: sampling locations 14, 13, 15 for <2012, 2012 and 2013, respectively. This may indicate that within the total carbon pool, organic carbon (OC) represents the major reservoir. 
On the other hand, elemental carbon (EC) concentrations did not exceed $0.2 \mathrm{mg} \mathrm{g}^{-1}$, which indicates that EC contributed slightly to TC. This might be explained by the fact that EC is mostly contained in the fine fraction of the aerosols (Zhang et al., 2020) that is less easily deposited compared to the coarse fraction. While diesel road traffic has been identified elsewhere as one of the major sources of EC (e.g., Bond et al., 2013; Yamagami et al., 2019) our highest EC concentrations were recorded during the heating season (one-year old samples; Fig. 7(B)), when emission from road traffic is not expected to dominate. During the heating season the generally high carbon concentration in the atmosphere are related to low temperatures and meteorological conditions that cause poor dispersion conditions that lead to the condensation of semi volatile species (Galindo et al., 2019). Hypothesizing that i) diesel was a major source of EC and ii) the yearly road traffic was somewhat constant in the region, it was expected that EC concentrations would be similar over the different sampling periods. Results also indicated that EC concentrations differed between sampling location, and moreover seemed to increase with the needle exposure time to air pollution (Fig. 7). The highest EC concentrations were measured in aerosols deposited on needles corresponding to sampling locations 4 and 12, in needles older than 2012 (Fig. 7(C)). Sampling location 12 is on a peak, hinting that the high EC concentrations may be associated to long-distance air masses transport. For sample 4, the contamination seemed to be related to home heating from the nearby habitations, although road traffic may also be a non-negligible source of contamination. For samples with shorter exposure times (Figs. $7(A)$ and $7(B)$ ) the highest EC concentrations were observed at sampling points 15 and 12 , both located on peaks that may again indicate the impact of transboundary pollutants (i.e., incomplete fossil fuel combustion) from nearby industrial plants. Coal combustion from home heating may also contribute to the EC budget, but delineating its impact zone is somewhat difficult at this point.

Fig. 8 reports the covariations between $\delta^{13} C_{T C}$ and EC in aerosols deposited on the surface of our needle samples. Fields A, B and C delimit samples that were collected close to residential buildings (orange arrows, 3 and 4) and at elevated locations (blues arrows, 11 and 15) for different groups of needle samples (2013, 2012 and older than 2012, respectively).

Although we previously discussed the possibility that samples older than 2012 may be impacted by the accumulation of organic particles over time, results indicated statistically significant ( $p<$ 0.05) differences between 6-months-old samples (2013) and one-year-old samples (2012) (Fig. 8). Results in Fig. 8 show that for some needle samples we can observe noticeable differences between the different needles generations. For example, samples from locations 3 and 4 showed a combined increase in their respective EC concentrations and $\delta^{13} C_{T C}$ from 2012 to 2013 that can be interpreted as an increasing impact of emissions from home heating. For samples 11 and 15 (elevated areas) the signal probably corresponds to aerosol contamination transported from nearby urbanized areas.

Samples 9 and 10 have characteristics in Fig. 8 that are similar to those of fields $D$ and E, representative of emissions from road traffic. Our results suggest that differences are only noticeable at sampling locations dominated by a single source of pollution. Interestingly, the $\delta^{13} C_{\mathrm{TC}}$ values are increasing with age at location 10 . As location 10 is closer to residential buildings, this trend might be explained by inefficient coal combustion, as an accumulation of coal soot $\left(\delta^{13} \mathrm{C}=-24.5 \%\right.$ o) will increase the carbon isotope composition. In turn, samples at location 9 were collected right next to a busy road. Hence, the influence of diesel particles $(-28.3 \%$ ) or unleaded fuel particles $(-26.8 \%$ o $)$ were clearly identified. For both fields $D$ and $E \delta^{13} C_{T C}$ differences were observed between samples from 2012 and 2013: one-year-old samples (2012) were characterized by slightly more positive values than 6-months-old samples (2013); -30.2\%o (location 9), -29.0\%o (location 10) and -31.0\%o (location 9), -29.6\% (location 10), respectively. This decrease in $\delta^{13} \mathrm{C}$ between 2012 and 2013 may be explained by the fact that in 2013 the heating season signal was not preserved. Most terrestrial plants ( $C_{3}$ plants) are characterized by $\delta^{13} C$ values ranging from $-34 \%$ o to $-24 \%$ o (Šturm et al., 2012). Thus, the $\delta^{13} \mathrm{C}$ of samples that only reflect the growing season will be more negative than those exposed for longer periods of time. Here, we observed more positive $\delta^{13} \mathrm{C}$ values resulting of fossil fuel or biomass combustion in samples exposed for one or more years.

Additionally, to confront our conclusions we conducted a Principal Component Analysis. Results showed that the first 2 factors explained $84 \%$ (determined by a Scree test) of the observed variations among the variables: 58\% for Factor 1 and 26\% for Factor 2 (Table 3). The remaining $16 \%$ constituted a random noise that is not interpretable using this technique. Factor 1 positively 
correlates aerosol, TC and OC concentrations, while Factor 2 is controlled by EC concentrations and $\delta^{13} \mathrm{C}$. As Factor 2 yields a positive correlation between $\delta^{13} \mathrm{C}$ and $\mathrm{EC}$ concentrations, it can be associated with the combustion processes whereas Factor 1 represents all other processes.
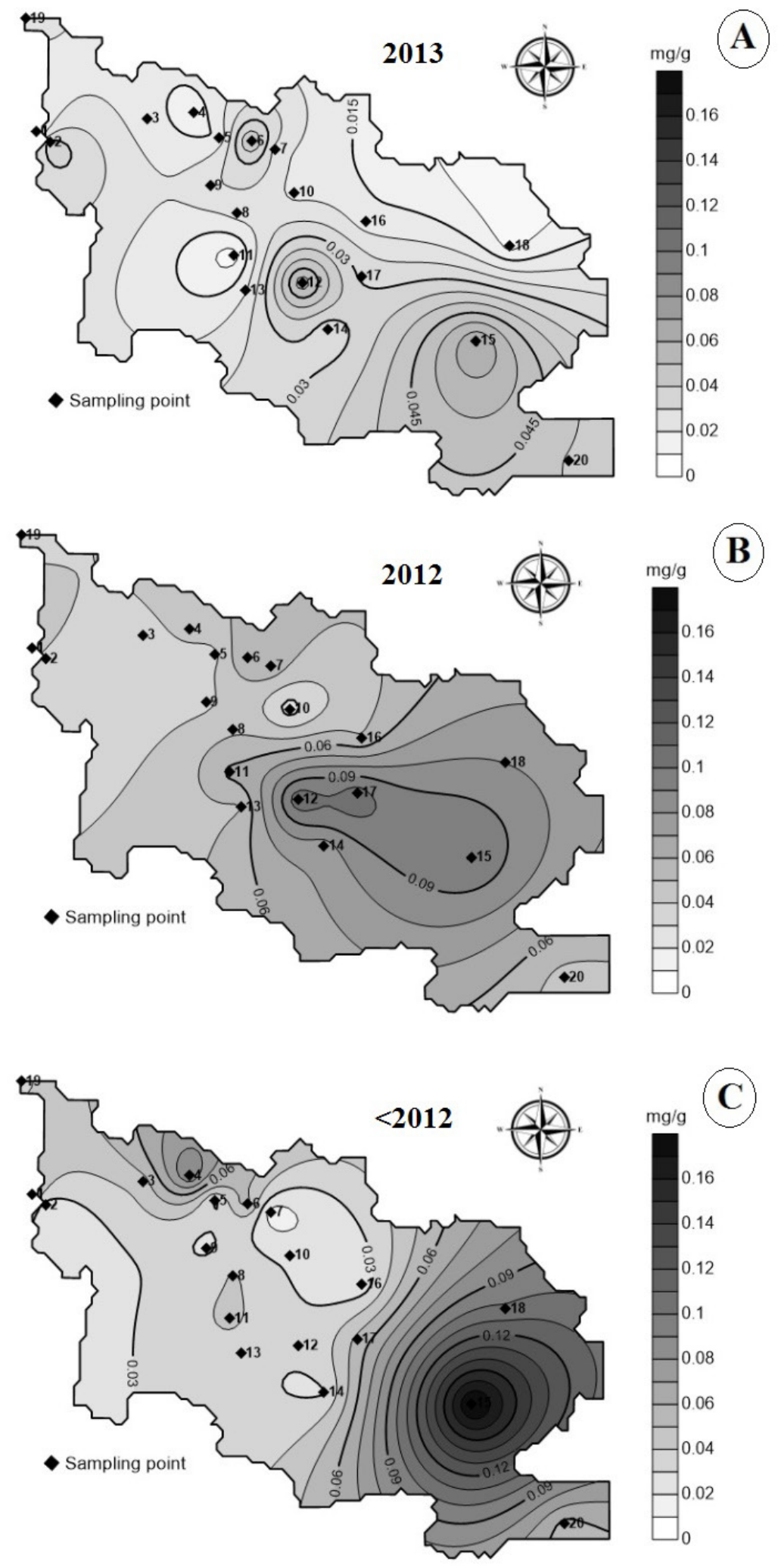

Fig. 7. Elemental carbon concentrations at the surface of needle samples. (A) 2013 samples, (B) 2012 samples, (C) $<2012$ samples. 


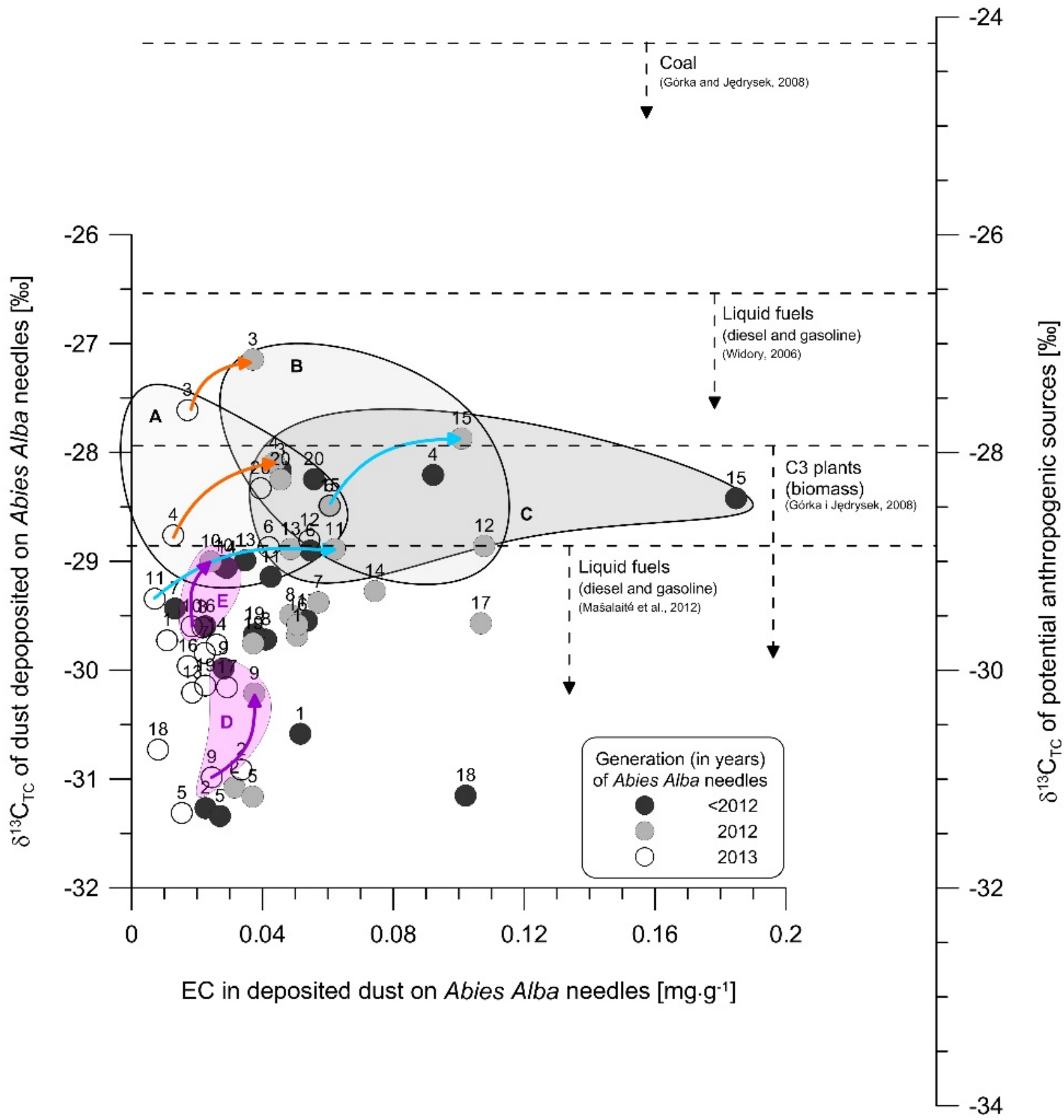

Fig. 8. Relationship between $\delta^{13} C_{T C}$ and elemental carbon (EC) in deposited aerosols. Fields A (2013), B (2012) and C (<2012) correspond to samples collected close to residential buildings and at the Park's peaks. Fields $D$ and $E$ represent points located close to roads $(9,10)$. Arrows represent changes in the carbon isotope compositions between years 2012 and 2013 (orange for residential areas, blue for peaks). The typical $\delta^{13} \mathrm{C}$ ranges for potential anthropogenic sources are taken from the literature.

Table 3. Results of the Principal Component Analysis. Statistically significant values are identified in bold.

Factor loads (Varimax normalized rotation)

Principal Component Analysis Statistically important loads $>0.60$

\begin{tabular}{lll} 
& Factor 1 & Factor 2 \\
\hline Aerosol concentration $\left[\mathrm{mg} \mathrm{g}^{-1}\right]$ & $\mathbf{0 . 9 1}$ & 0.13 \\
$\mathrm{TC}\left[\mathrm{mg} \mathrm{g}^{-1}\right]$ & $\mathbf{0 . 9 8}$ & 0.10 \\
$\mathrm{EC}\left[\mathrm{mg} \mathrm{g}^{-1}\right]$ & 0.41 & $\mathbf{0 . 6 8}$ \\
$\mathrm{OC}\left[\mathrm{mg} \mathrm{g}^{-1}\right]$ & $\mathbf{0 . 9 8}$ & 0.06 \\
$\delta^{13} \mathrm{CTC}_{\text {Factor contribution [\%] }}$ & -0.10 & $\mathbf{0 . 9 0}$ \\
\hline
\end{tabular}




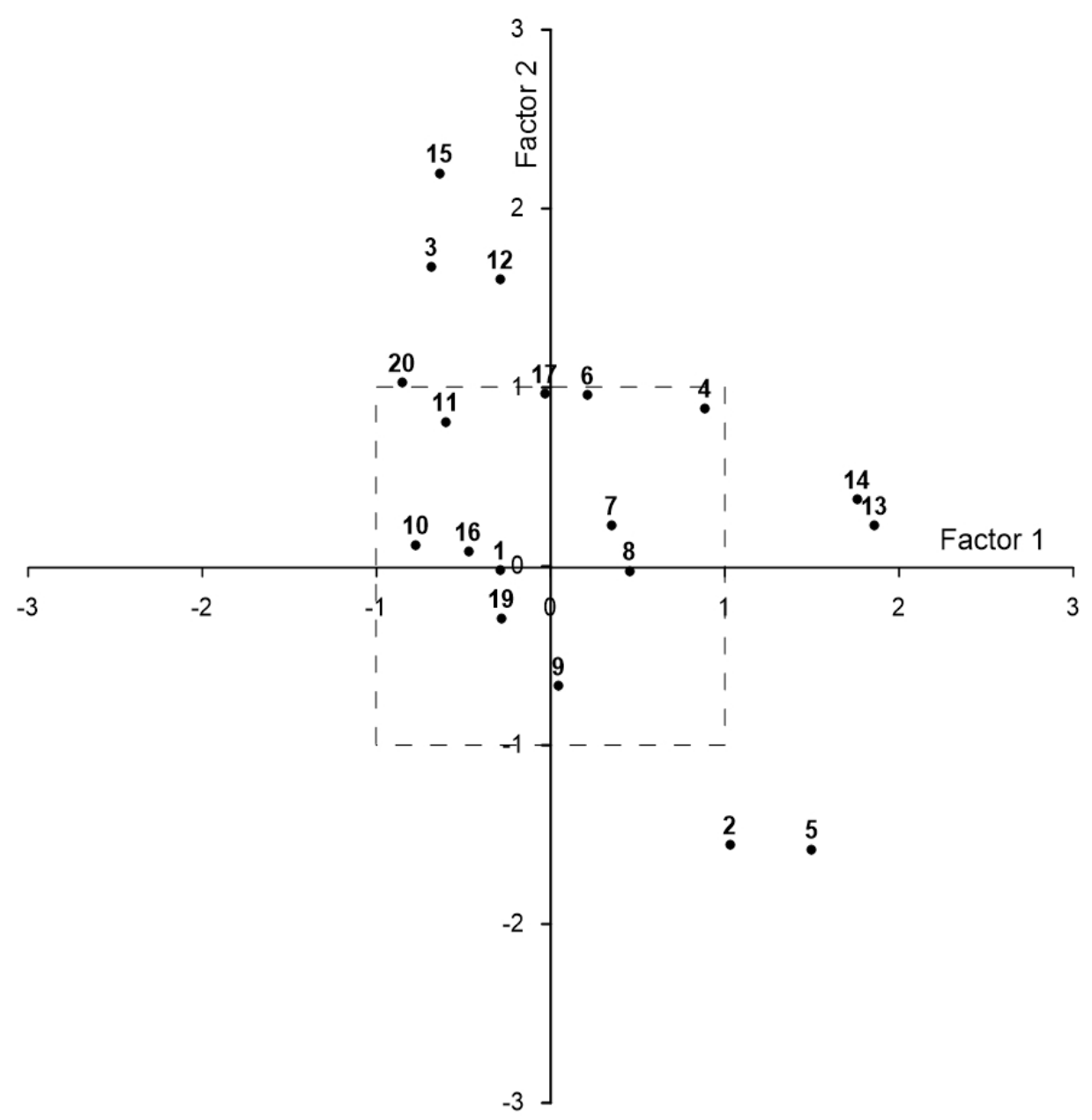

Fig. 9. Factor scores obtained for the one-year old needle samples at the different sampling locations.

Fig. 9 reports the factor scores obtained for each sample along Factors 1 and 2. While factor scores ranging between -1 and +1 indicate an average intensity for the controlling process, values $>+1$ indicate that the process is dominating and inversely a value $<-1$ indicates that the process is not contributing. Results (Fig. 9) show that Factor 2, associated to combustion processes, dominates for samples collected on peaks (sampling locations 12 and 15) or high altitudes (sampling location 11). This is also true for samples collected nearby inhabited areas (sampling locations 3, 4 and 6). However, factor scores for Factor 2 in samples collected close to roads did not yield high values, which may indicate that among the combustion processes associated to this factor, road traffic is not the most contributing.

\section{CONCLUSIONS}

Here, we investigated and demonstrated that Abies alba needles are reliable bioindicators to identify sources of aerosol contamination for a given area. These bio-passive samplers help to avoid the use and maintenance of expensive automatic samplers in inaccessible areas where air quality monitoring is required. Here, we are proposing that, in areas where they grow, fir needles are a good air quality monitoring tool. This applies especially to mountains and woody areas where using specialized equipment is not possible or very difficult due to altitude, the lack of access to electricity or a limited access for people. Still, this method requires that the accumulated mass of particles deposited on the surface of the needles be quantified, as an excess can block the suprastomatal chambers and alter the carbon isotope signal. Using the example of the Świetokrzyski National Park (Holy Cross Voivodship, Poland) our results show that the highest 
$\delta^{13} \mathrm{C}$ values were observed at locations that were: a) at high elevations, b) near inhabited areas and c) outside the park. Using a PCA approach we identified that combustion processes mostly control their carbon contents. Our study also demonstrates that one-year-old needles are the most reliable samples. While part of the aerosols deposited on the needles can be removed by wind or rain, combining carbon stable isotopes and geochemical analysis provides a reliable assessment of the aerosol mass and greatly helps identifying the major sources of air pollution. Our results identified emission from home heating, road traffic and transport from nearby urbanized areas as the major sources of pollution in the ŚNP. Finally, we do not recommend using needles older than one year due to a high accumulation of organic particles that inherently alters the information that could be retrieved about obtained air pollution. The analysis of TC/OC/EC and of SEM images suggest that for these older samples, interpretation is rendered difficult and imprecise. At the same time, it still arises the need for further studies, especially inter-comparisons with reference methods.

\section{ACKNOWLEDGEMENTS}

This research was supported by the University of Wroclaw grants 0401/1017/18 and 501/0410/2988/18. The authors would like to thank Monika Ciężka, Anna Łubek and Agnieszka Winiszewska for helping with the field work and sample collection. We wish to express sincere gratitude to prof. Gregory D. Hoke for helping to improve the manuscript.

\section{SUPPLEMENTARY MATERIAL}

Supplementary material for this article can be found in the online version at https://doi. org/10.4209/aaqr.210097

\section{REFERENCES}

Aguilera, J., Whigham, L.D. (2018). Using the ${ }^{13} \mathrm{C} /{ }^{12} \mathrm{C}$ carbon isotope ratio to characterise the emission sources of airborne particulate matter: A review of literature. Isot. Environ. Health Stud. 54, 573-587. https://doi.org/10.1080/10256016.2018.1531854

Al-Alawi, M.M., Mandiwana, K.L. (2007). The use of Aleppo pine needles as a bio-monitor of heavy metals in the atmosphere. J. Hazard. Mater. 148, 43-46. https://doi.org/10.1016/j.jhaz mat.2007.02.001

Ares, A., Aboal, J.R., Carballeira, A., Giordano, S., Adamo, P., Fernández, J.A. (2012). Moss bag biomonitoring: A methodological review. Sci. Total Environ. 432, 143-158. https://doi.org/10. 1016/j.scitotenv.2012.05.087

Ataabadi, M., Hoodaji, M., Najafi, P. (2011). Biomonitoring of some heavy metal contaminations from a steel plant by above ground plants tissue. Afr. J. Biotechnol. 10, 4127-4132. https://doi.org/10.5897/AJB10.2452

Atkinson, R.W., Mills, I.C., Walton, H.A., Anderson, H.R. (2015). Fine particle components and health - A systematic review and meta-analysis of epidemiological time series studies of daily mortality and hospital admissions. J. Exposure Sci. Environ. Epidemiol. 25, 208-214. https://doi.org/10.1038/jes.2014.63

Bačić, T., Lynch, A.H., Cutler, D. (1999). Reactions to cement factory dust contamination by Pinus halepensis needles. Environ. Exp. Bot. 41, 155-166. https://doi.org/10.1016/S0098-8472(98)0 0060-4

Bartz, W., Górka, M., Rybak, J., Rutkowski, R., Stojanowska, A. (2021). The assessment of effectiveness of SEM-EDX and ICP-MS methods in the process of determining the mineralogical and geochemical composition of particulate matter deposited on spider webs. Chemosphere 278, 130454. https://doi.org/10.1016/j.chemosphere.2021.130454

Bond, T.C., Doherty, S.J., Fahey, D.W., Forster, P.M., Berntsen, T., DeAngelo, B.J., Flanner, M.G., Ghan, S., Kärcher, B., Koch, D., Kinne, S., Kondo, Y., Quinn, P.K., Sarofim, M.C., Schultz, M.G., Schulz, M., Venkataraman, C., Zhang, H., Zhang, S., Bellouin, N., et al. (2013). Bounding the role 
of black carbon in the climate system: A scientific assessment. J. Geophys. Res. 118, 53805552. https://doi.org/10.1002/jgrd.50171

Brendel, O., Handley, L., Griffiths, H. (2003). The $\delta^{13} \mathrm{C}$ of Scots pine (Pinus sylvestris L.) needles: Spatial and temporal variations. Ann. For. Sci. 60, 97-104. https://doi.org/10.1051/forest:200 3001

Buschhaus, C., Jetter, R. (2011). Composition differences between epicuticular and intracuticular wax substructures: How do plants seal their epidermal surfaces? J. Exp. Bot. 62, 841-853. https://doi.org/10.1093/jxb/erq366

Cattell, R.B. (1966). The screen test for the number of factors. Multivar. Behav. Res. 1, 245-276.

Cavalli, F., Viana, M., Yttri, K.E., Genberg, J., Putaud, J.P. (2010). Toward a standardised thermaloptical protocol for measuring atmospheric organic and elemental carbon: The EUSAAR protocol. Atmos. Meas. Tech. 3, 79-89. https://doi.org/10.5194/amt-3-79-2010

Central Statistical Office (2013). Transport: wyniki działalności 2012.

Ciężka, M., Kossowska, M., Paneth, P., Górka, M. (2016). Carbon, Nitrogen and Sulphur concentration and $\delta^{13} \mathrm{C}, \delta^{15} \mathrm{~N}$ values in Hypogymnia physodes within the montane area - preliminary data. Geosci. Rec. 2, 24-32. https://doi.org/10.1515/georec-2016-0004

Ciężka, M.M., Górka, M., Modelska, M., Tyszka, R., Samecka-Cymerman, A., Lewińska, A., Łubek, A., Widory, D. (2018). The coupled study of metal concentrations and electron paramagnetic resonance (EPR) of lichens (Hypogymnia physodes) from the Świętokrzyski National Parkenvironmental implications. Environ. Sci. Pollut. Res. 25, 25348-25362. https://doi.org/10.10 07/s11356-018-2586-x

Conti, M.E., Cecchetti, G. (2001). Biological monitoring: Lichens as bioindicators of air pollution assessment - A review. Environ. Pollut. 114, 471-492. https://doi.org/10.1016/S0269-7491(00 )00224-4

Cuna, S., Balas, G., Hauer, E. (2007). Effects of natural environmental factors on $\delta^{13} \mathrm{C}$ of lichens. Isot. Environ. Health Stud. 43, 95-104. https://doi.org/10.1080/10256010701362401

Drever, J. (1997). The geochemistry of natural waters--Surface and groundwater environments (3rd). In Eos, Transactions American Geophysical Union.

Estrabou, C., Filippini, E., Soria, J. P., Schelotto, G., Rodriguez, J.M. (2011). Air quality monitoring system using lichens as bioindicators in Central Argentina. Environ. Monit. Assess. 182, 375383 https://doi.org/10.1007/s10661-011-1882-4

European Environment Agency (EEA) (2018). Air quality in Europe - 2018 report. Publications Office of the European Union, Luxembourg. https://doi.org/10.2800/777411

European Environment Agency (EEA) (2019). Air quality in Europe - 2019 report. Publications Office of the European Union, Luxembourg. https://doi.org/10.2800/822355

Freyer, H.D. (1978). Seasonal trends of $\mathrm{NH}_{4}^{+}$and $\mathrm{NO}_{3}^{-}$nitrogen isotope composition in rain collected at Jülich, Germany. Tellus 30, 83-92. https://doi.org/10.3402/tellusa.v30i1.10319

Gagen, M., McCarroll, D., Loader, N.J., Robertson, I., Jalkanen, R., Anchukaitis, K.J. (2007). Exorcising the "segment length curse": Summer temperature reconstruction since AD 1640 using non-detrended stable carbon isotope ratios from pine trees in northern Finland. Holocene 17, 435-446. https://doi.org/10.1177/0959683607077012

Galindo, N., Yubero, E., Clemente, A., Nicolás, J.F., Navarro-Selma, B., Crespo, J. (2019). Insights into the origin and evolution of carbonaceous aerosols in a mediterranean urban environment. Chemosphere 235, 636-642. https://doi.org/10.1016/j.chemosphere.2019.06.202

GDDKiA (2015). General Traffic Measurement.

Gerdol, R., Marchesini, R., lacumin, P., Brancaleoni, L. (2014). Monitoring temporal trends of air pollution in an urban area using mosses and lichens as biomonitors. Chemosphere 108, 388395. https://doi.org/10.1016/j.chemosphere.2014.02.035

GIOŚ (2019). Roczna ocena jakości powietrza w województwie Świętokrzyskim. Raport wojewódzki za rok 2018.

Górka, M., Jędrysek, M.O. (2008). $\delta^{13} \mathrm{C}$ of organic atmospheric dust deposited in Wrocław (SW Poland): Critical remarks on the passive method. Geological Quarterly.

Górka, M., Zwolińska, E., Malkiewicz, M., Lewicka-Szczebak, D., Jędrysek, M.O. (2012). Carbon and nitrogen isotope analyses coupled with palynological data of $\mathrm{PM}_{10}$ in Wroclaw city (SW Poland) - assessment of anthropogenic impact. Isot. Environ. Health Stud. 48, 327-344. https://doi.org/10.1080/10256016.2012.639449 
Górka, M., Bartz, W., Rybak, J. (2018). The mineralogical interpretation of particulate matter deposited on Agelenidae and Pholcidae spider webs in the city of Wrocław (SW Poland): A preliminary case study. J. Aerosol Sci. 123, 63-75. https://doi.org/10.1016/j.jaerosci.2018.06. 008

Górka, M., Bartz, W., Skuridina, A., Potysz, A. (2020). Populus nigra italica leaves as a valuable tool for mineralogical and geochemical interpretation of inorganic atmospheric aerosols' genesis. Atmosphere 11, 1126. https://doi.org/10.3390/atmos11101126

Holy, M., Leblond, S., Pesch, R., Schröder, W. (2009). Assessing spatial patterns of metal bioaccumulation in French mosses by means of an exposure index. Environ. Sci. Pollut. Res. 16, 499-507. https://doi.org/10.1007/s11356-009-0146-0

Hose, G.C., James, J.M., Gray, M.R. (2002). Spider webs as environmental indicators. Environ. Pollut. 120, 725-733. https://doi.org/10.1016/S0269-7491(02)00171-9

Husain, L., Dutkiewicz, V.A., Khan, A.J., Ghauri, B.M. (2007). Characterization of carbonaceous aerosols in urban air. Atmos. Environ. 41, 6872-6883. https://doi.org/10.1016/j.atmosenv.20 07.04.037

Johnson, R.J. (1978). Multivariate Statistical Analysis in Geography. Longmans, London.

Kłos, A., Rajfur, M., Wacławek, M., Wacławek, W. (2007). Heavy metal sorption in the lichen cationactive layer. Bioelectrochemistry 71, 60-65. https://doi.org/10.1016/j.bioelechem.200 6.12 .005

Kłos, A., Ziembik, Z., Rajfur, M., Dołhańczuk-Śródka, A., Bochenek, Z., Bjerke, J.W., Tømmervik, H., Zagajewski, B., Ziółkowski, D., Jerz, D., Zielińska, M., Krems, P., Godyń, P., Marciniak, M., Świsłowski, P. (2018). Using moss and lichens in biomonitoring of heavy-metal contamination of forest areas in southern and north-eastern Poland. Sci. Total Environ. 627, 438-449. https://doi.org/10.1016/j.scitotenv.2018.01.211

Kucbel, M., Sýkorová, B., Růžičková, J. (2016). Carbonaceous particles in the air of the MoravianSilesian Region, Czech Republic. Perspect. Sci. 7, 333-336. https://doi.org/10.1016/j.pisc.2015. 11.051

Lehndorff, E., Schwark, L. (2004). Biomonitoring of air quality in the Cologne Conurbation using pine needles as a passive sampler - Part II: Polycyclic aromatic hydrocarbons (PAH). Atmos. Environ. 38, 3793-3808. https://doi.org/10.1016/j.atmosenv.2004.03.065

Leśniewicz, A., Zyrnicki, W. (2000). Multielemental analysis of yew, pine and spruce needles by ICP-AES. Int. J. Environ. Anal. Chem. 77, 147-158. https://doi.org/10.1080/03067310008032678

Lewandowska, A.U., Bełdowska, M., Witkowska, A., Falkowska, L., Wiśniewska, K. (2018). Mercury bonds with carbon $(\mathrm{OC}$ and $\mathrm{EC})$ in small aerosols $\left(\mathrm{PM}_{1}\right)$ in the urbanized coastal zone of the Gulf of Gdansk (southern Baltic). Ecotoxicol. Environ. Saf. 157, 350-357. https://doi.org/ 10.1016/j.ecoenv.2018.03.097

Lim, S., Yang, X., Lee, M., Li, G., Gao, Y., Shang, X., Zhang, K., Czimczik, C.I., Xu, X., Bae, M.S., Moon, K.J., Jeon, K. (2020). Fossil-driven secondary inorganic $\mathrm{PM}_{2.5}$ enhancement in the North China Plain: Evidence from carbon and nitrogen isotopes. Environ. Pollut. 266, 115163. https://doi.org/10.1016/j.envpol.2020.115163

Lucking, A.J., Lundbäck, M., Barath, S.L., Mills, N.L., Sidhu, M.K., Langrish, J.P., Boon, N.A., Pourazar, J., Badimon, J.J., Gerlofs-Nijland, M.E., Cassee, F.R., Boman, C., Donaldson, K., Sandstrom, T., Newby, D.E., Blomberg, A. (2011). Particle Traps Prevent Adverse Vascular and Prothrombotic Effects of Diesel Engine Exhaust Inhalation in Men. Circulation 123, 1721-1728. https://doi.org/10.1161/CIRCULATIONAHA.110.987263

Manly, B.F.J. (1998). Multivariate statistical methods. Capman and Hall, New York.

Mauri, A., de Rigo, D., Caudullo, G. (2016). Abies alba in Europe: distribution, habitat, usage and threats. in: San-Miguel-Ayanz, J., de Rigo, D., Caudullo, G., Houston Durrant, T., Mauri, A. (Eds.), European Atlas of Forest Tree Species. Publications Office of the European Union, Luxembourg, pp. e01493b+.

Maxhuni, A., Lazo, P., Kane, S., Qarri, F., Marku, E., Harmens, H. (2016). First survey of atmospheric heavy metal deposition in Kosovo using moss biomonitoring. Environ. Sci. Pollut. Res. 23, 744-755. https://doi.org/10.1007/s11356-015-5257-1

McCarroll, D., Pawellek, F. (2001). Stable carbon isotope ratios of Pinus sylvestris from northern Finland and the potential for extracting a climate signal from long Fennoscandian chronologies. Holocene 11, 517-526. https://doi.org/10.1191/095968301680223477 
Mills, N.L., Miller, M.R., Lucking, A.J., Beveridge, J., Flint, L., Boere, A.J.F., Fokkens, P.H., Boon, N.A., Sandstrom, T., Blomberg, A., Duffin, R., Donaldson, K., Hadoke, P.W.F., Cassee, F.R., Newby, D.E. (2011). Combustion-derived nanoparticulate induces the adverse vascular effects of diesel exhaust inhalation. Eur. Heart J. 32, 2660-2671. https://doi.org/10.1093/eurheartj/ehr195

Morera-Gómez, Y., Alonso-Hernández, C.M., Cartas-Águila, H.A., Santamaría, J.M., Elustondo, D. Lasheras, E., Bagur, M., Widory, D. (2020). Elucidating the sources and dynamics of PM10 aerosols in Cienfuegos (Cuba) using their multi-stable and radioactive isotope and ion compositions. Atmos. Res. 243, 105038. https://doi.org/10.1016/j.atmosres.2020.105038

Morera-Gómez, Y., Santamaría, J.M., Elustondo, D., Alonso-Hernández, C.M., Widory, D. (2018). Carbon and nitrogen isotopes unravels sources of aerosol contamination at Caribbean rural and urban coastal sites. Sci. Total Environ. 642, 723-732. https://doi.org/10.1016/j.scitotenv. 2018.06.106

Murillo, J.H., Rojas Marin, J.F., Roman, S.R., Beita Guerrero, V.H., Arias, D.S., Ramos, A.C., Gonzalez, B.C., Baumgardner, D.G. (2013). Temporal and spatial variations in organic and elemental carbon concentrations in $\mathrm{PM}_{10} / \mathrm{PM}_{2.5}$ in the metropolitan area of Costa Rica, Central America. Atmos. Pollut. Res. 4, 53-63. https://doi.org/10.5094/APR.2013.006

Muukkonen, P., Lehtonen, A. (2004). Needle and branch biomass turnover rates of Norway spruce (Picea abies). Can. J. For. Res. 34, 2517-2527. https://doi.org/10.1139/X04-133

Nowak, D.J., Hirabayashi, S., Bodine, A., Hoehn, R. (2013). Modeled PM 2.5 removal by trees in ten U.S. cities and associated health effects. Environ. Pollut. 178, 395-402. https://doi.org/10.101 6/j.envpol.2013.03.050

Olszewski, J., Szałach, G., Żarnowiecki, G. (2000). Monografia Świętokrzyskiego Parku Narodowego. 17-29.

Ozdemir, H., Pozzoli, L., Kindap, T., Demir, G., Mertoglu, B., Mihalopoulos, N., Theodosi, C., Kanakidou, M., Im, U., Unal, A. (2014). Spatial and temporal analysis of black carbon aerosols in Istanbul megacity. Sci. Total Environ. 473-474, 451-458. https://doi.org/10.1016/j.scitoten v.2013.11.102

Pazdur, A., Kuc, T., Pawełczyk, S., Piotrowska, N., Sensuła, B., Rozanski, K. (2013). Carbon isotope composition of atmospheric carbon dioxide in southern Poland: Imprint of anthropogenic $\mathrm{CO}_{2}$ emissions in regional biosphere. Radiocarbon 55, 848-864. https://doi.org/10.1017/s0033822 20005801x

Prajapati, S.K., Tripathi, B.D. (2008). Seasonal variation of leaf dust accumulation and pigment content in plant species exposed to urban particulates pollution. J. Environ. Qual. 37, 865-870. https://doi.org/10.2134/jeq2006.0511

R Core Team (2013). R: A language and environment for statistical computing. R Foundation for Statistical Computing. Vienna.

Sawidis, T., Breuste, J., Mitrovic, M., Pavlovic, P., Tsigaridas, K. (2011). Trees as bioindicator of heavy metal pollution in three European cities. Environ. Pollut. 159, 3560-3570. https://doi.org/10.1016/j.envpol.2011.08.008

Schauer, J.J., Rogge, W.F., Hildemann, L.M., Mazurek, M.A., Cass, G.R., Simoneit, B.R.T. (2007) Source apportionment of airborne particulate matter using organic compounds as tracers. Atmos. Environ. 41, 241-259. https://doi.org/10.1016/j.atmosenv.2007.10.069

Schwarz, J., Chi, X., Maenhaut, W., Civiš, M., Hovorka, J., Smolík, J. (2008). Elemental and organic carbon in atmospheric aerosols at downtown and suburban sites in Prague. Atmos. Res. 90, 287-302. https://doi.org/10.1016/j.atmosres.2008.05.006

Sensuła, B., Michczyński, A., Piotrowska, N., Wilczyński, S. (2018). Anthropogenic $\mathrm{CO}_{2}$ emission records in scots pine growing in the most industrialized region of Poland from 1975 to 2014 Radiocarbon 60, 1041-1053. https://doi.org/10.1017/RDC.2018.59

Shetekauri, S., Chaligava, O., Shetekauri, T., Kvlividze, A., Kalabegishvili, T., Kirkesali, E., Frontasyeva, M., Chepurchenko, O., Tselmovich, V. (2018). Biomonitoring Air Pollution Using Mossin Georgia. Pol. J. Environ. Stud. 27, 2259-2266. https://doi.org/10.15244/pjoes/73798

Squires, V.R. (2016). Dust particles and aerosols: Impact on biota "A review” (Part II). J. Rangeland Sci. 6, 177-193.

Stojanowska, A., Rybak, J., Bożym, M., Olszowski, T., Bihałowicz, J.S. (2020). Spider webs and lichens as bioindicators of heavy metals: A comparison study in the vicinity of a copper smelter (Poland). Sustainability 12, 8066. https://doi.org/10.3390/su12198066 
Stojanowska, A., Mach, T., Olszowski, T., Bihałowicz, J.S., Górka, M., Rybak, J., Rajfur, M., Świsłowski, P. (2021). Air pollution research based on spider web and parallel continuous particulate monitoring-A comparison study coupled with identification of sources. Minerals 11, 812. https://doi.org/10.3390/min11080812

Šturm, M., Vreča, P., Krajcar Bronić, I. (2012). Carbon isotopic composition $\left(\delta^{13} \mathrm{C}\right.$ and ${ }^{14} \mathrm{C}$ activity) of plant samples in the vicinity of the Slovene nuclear power plant. J. Environ. Radioac. 110, 24-29. https://doi.org/10.1016/j.jenvrad.2012.01.021

Teper, E. (2009). Dust-particle migration around flotation tailings ponds: Pine needles as passive samplers. Environ. Monit. Assess. 154, 383-391. https://doi.org/10.1007/s10661-008-0405-4

van der Merwe, N.J., Medina, E. (1991). The canopy effect, carbon isotope ratios and foodwebs in amazonia. J. Archaeol. Sci. 18, 249-259. https://doi.org/10.1016/0305-4403(91)90064-V

Vladimirovna Afanasyeva, L., Ayushievna Ayushina, T. (2019). Accumulation of heavy metals and biochemical responses in Siberian larch needles in urban area. Ecotoxicology 28, 578-588. https://doi.org/10.1007/s10646-019-02055-9

Wang, L., Gong, H., Liao, W., Wang, Z. (2015). Accumulation of particles on the surface of leaves during leaf expansion. Sci. Total Environ. 532, 420-434. https://doi.org/10.1016/j.scitotenv.20 15.06.014

Widory, D., Roy, S., Le Moullec, Y., Goupil, G., Cocherie, A., Guerrot, C. (2004). The origin of atmospheric particles in Paris: A view through carbon and lead isotopes. Atmos. Environ. 38, 953-961. https://doi.org/10.1016/j.atmosenv.2003.11.001

WIOŚ (2012). Air quality assessment in the Holly Cross Voivodeship in 2011.

WIOŚ (2013). Air quality assessment in the Holly Cross Voivodeship in 2012.

WIOŚ (2014). Air quality assessment in the Holly Cross Voivodeship in 2013.

Wiśniewska, K., Lewandowska, A.U., Staniszewska, M. (2019). Air quality at two stations (Gdynia and Rumia) located in the region of Gulf of Gdansk during periods of intensive smog in Poland. Air Qual. Atmos. Health 12, 879-890. https://doi.org/10.1007/s11869-019-00708-6

Wuytack, T., Verheyen, K., Wuyts, K., Kardel, F., Adriaenssens, S., Samson, R. (2010). The potential of biomonitoring of air quality using leaf characteristics of white willow (Salix alba L.). Environ. Monit. Assess. 171, 197-204. https://doi.org/10.1007/s10661-009-1271-4

Xu, Z., Wen, T., Li, X., Wang, J., Wang, Y. (2015). Characteristics of carbonaceous aerosols in Beijing based on two-year observation. Atmos. Pollut. Res. 6, 202-208. https://doi.org/10.509 4/APR.2015.024

Yamagami, M., Ikemori, F., Nakashima, H., Hisatsune, K., Osada, K. (2019). Decreasing trend of elemental carbon concentration with changes in major sources at Mega city Nagoya, Central Japan. Atmos. Environ. 199, 155-163. https://doi.org/10.1016/j.atmosenv.2018.11.014

Yang, J., Chang, Y., Yan, P. (2015). Ranking the suitability of common urban tree species for controlling PM2.5 pollution. Atmos. Pollut. Res. 6, 267-277. https://doi.org/10.5094/APR.2015.031

Zeisler-Diehl, V., Müller, Y., Schreiber, L. (2018). Epicuticular wax on leaf cuticles does not establish the transpiration barrier, which is essentially formed by intracuticular wax. J. Plant Physiol. 227, 66-74. https://doi.org/10.1016/j.jplph.2018.03.018

Zhang, F., Guo, H., Chen, Y., Matthias, V., Zhang, Y., Yang, X., Chen, J. (2020). Size-segregated characteristics of organic carbon (OC), elemental carbon (EC) and organic matter in particulate matter (PM) emitted from different types of ships in China. Atmos. Chem. Phys. 20, 15491564. https://doi.org/10.5194/acp-20-1549-2020

Zhang, H.Y., Hartmann, H., Gleixner, G., Thoma, M., Schwab, V.F. (2019). Carbon isotope fractionation including photosynthetic and post-photosynthetic processes in $\mathrm{C}_{3}$ plants: Low $\left[\mathrm{CO}_{2}\right]$ matters. Geochim. Cosmochim. Acta 245, 1-15. https://doi.org/10.1016/j.gca.2018.09.035

Zimnoch, M., Morawski, F., Kuc, T., Samek, L., Bartyzel, J., Gorczyca, Z., Skiba, A., Rozanski, K. (2020). Summer-winter contrast in carbon isotope and elemental composition of total suspended particulate matter in the urban atmosphere of Krakow, Southern Poland. Nukleonika 65, 181-191. https://doi.org/10.2478/nuka-2020-0029 